\title{
An ATM- and ATR-dependent checkpoint inactivates spindle assembly by targeting CEP63
}

\author{
Eloise Smith ${ }^{1}$, Donniphat Dejsuphong ${ }^{1,2}$, Alessia Balestrini ${ }^{1}$, Martin Hampel $^{3}$, Christof Lenz ${ }^{4}$, Shunichi Takeda ${ }^{2}$, \\ Alessandro Vindigni ${ }^{3}$ and Vincenzo Costanzo ${ }^{1,5}$
}

\section{Activation of the protein kinases ATM and ATR following} chromosomal breakage prevents initiation of DNA replication and entry into mitosis. However, the effects of ATM and ATR activation in cells already progressing through mitosis are poorly understood. Here we report that ATM and ATR activation induced by DNA double-strand breaks (DSBs) inhibits centrosome-driven spindle assembly in Xenopus laevis mitotic egg extract and somatic cells, delaying mitotic progression. Using a cDNA expression library to screen for ATM and ATR substrates, we identified centrosomal protein CEP63 as an ATM and ATR target required for normal spindle assembly. ATM and ATR phosphorylate Xenopus CEP63 (XCEP63) on Ser 560 and promote its delocalization from the centrosome. Suppression of ATM and ATR activity or mutation of XCEP63 Ser 560 to Ala prevented spindle assembly defects. Consistently, inactivation of the CEP63 gene in avian DT40 cells impaired spindle assembly and prevented ATM- and ATRdependent effects on mitosis. These data indicate that ATM and ATR control mitotic events in vertebrate cells by targeting CEP63 and centrosome dependent spindle assembly.

We have investigated the effects of ATM (ataxia telangiectasia mutated) and ATR (ATM and Rad3-related) activation on spindle assembly following chromosomal breakage. Sperm nuclei added to Xenopus cytostatic factor (CSF) egg extract, which is naturally arrested in mitosis ${ }^{1}$, initiated spindle assembly ${ }^{2}$ (Fig. 1a). To mimic the presence of DSBs and DNA gaps activating ATM and $\mathrm{ATR}^{3,4}$, restriction endonuclease EcoRI or linear DNA molecules consisting of poly-deossi-T annealed to polydeossi-A oligonucleotides (pA/pT) were added to egg extract. ATM and ATR activity was then monitored by detection of histone H2AX Ser 139 phosphorylation, which was inhibited by caffeine or by the ATM inhibitor Ku55933 (refs 3,5; Supplementary Information, Fig. S1a). Activation of ATM and ATR in mitosis was confirmed by the detection of ATM Ser 1981 and Chk1 phosphorylation (Supplementary Information, Fig. S1b). Following activation of ATM and ATR, spindle assembly was severely perturbed (Fig. 1a, b; Supplementary Information, Fig. S1c). Similar results were observed with NotI or doxorubicin (Supplementary Information, Fig. S1c). Microtubule polymerization from asters was unaffected (Fig. 1a) but aster number was increased (Fig. 1b), suggesting that maturation from aster to spindle was perturbed. Under these conditions, abnormal spindles with dispersed chromosomes and large aggregates of microtubules associated with chromosomes were observed (Fig. 1a, b; Supplementary Information, Fig. S1c). Caffeine or the ATM inhibitor Ku55933 alone, which also attenuates DSB-induced ATR activation ${ }^{6}$, prevented the occurrence of spindle defects (Fig. 1a, b; Supplementary Information, Fig. S1c). Spindle defects induced by exogenous DSBs ruled out a role of chromosome or kinetochore damage in the observed spindle assembly abnormalities (Supplementary Information, Fig. S1c). Similar results were obtained with bipolar spindles assembled after chromosome duplication in interphase extracts subsequently driven in mitosis ${ }^{2}$ (Supplementary Information, Fig. S1d). To test whether activation of ATM and ATR also affected spindle assembly in somatic cells, Xenopus XTC cells were synchronized in mitosis after being released from S-phase arrest in the presence of the proteasome inhibitor MG132 (ref. 7) and in the absence of microtubule depolymerizing agents that would mask the detection of spindle defects (Supplementary Information, Fig. S1e). After ionizing radiation (IR), a fraction of mitotic cells identified through histone H3 Ser 10 phosphorylation formed abnormal spindles and this could be prevented by inhibition of ATM and ATR (Fig. 1c, d; Supplementary Information, Fig. S1f).

To determine the mechanism of spindle assembly inhibition, we monitored mitotic status by measuring the activities of mitotic kinases such as Plx1 (ref. 8) and Cdk1-cyclin $\mathrm{B}^{1}$, which sustain each other through a Cdc25-dependent amplification loop ${ }^{8}$ that is also a target of ATM and ATR checkpoints inhibiting mitosis entry ${ }^{9}$. In contrast to its effects on mitosis entry, activation of ATM and ATR did not affect Cdk1-cyclin B and Plx1 activities in extracts that were already in mitosis and did not disrupt other extract features, such as Cdk1-cyclin B inactivation after addition of calcium ${ }^{1}$ (Fig. 2a, b). This suggests that ATM and ATR have different targets in mitosis. Consistently, addition of an excess

${ }^{5}$ Correspondence should be addressed to V.C. (e-mail: Vincenzo.Costanzo@cancer.org.uk). 
a

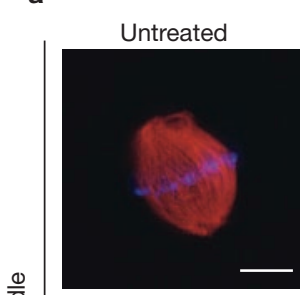

$\frac{\frac{0}{\overline{0}}}{\frac{\overline{0}}{0}}$
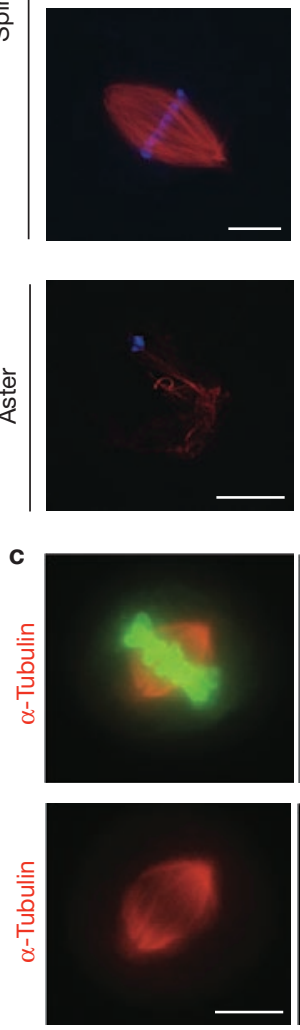

Untreated

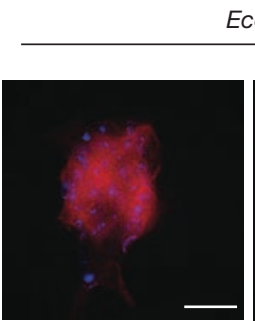

EcoRI

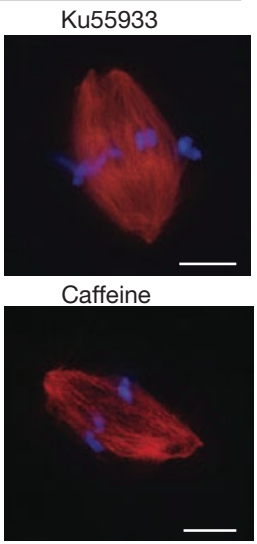

KU55933
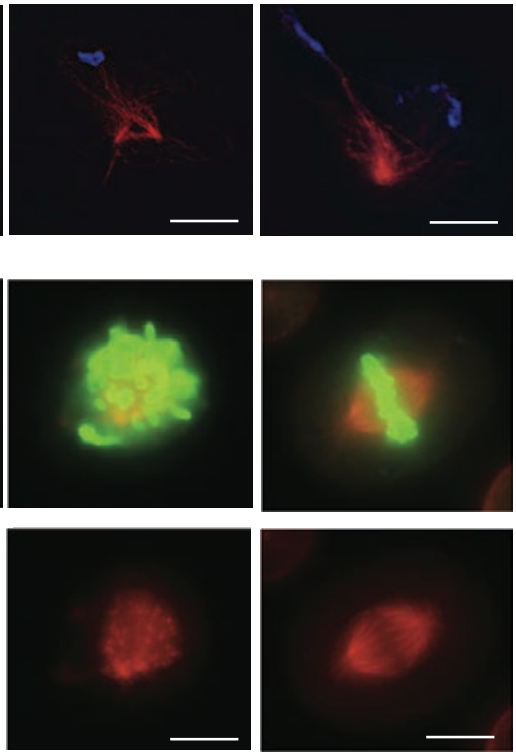

-Caffeine

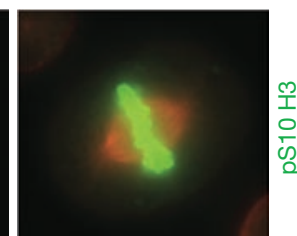

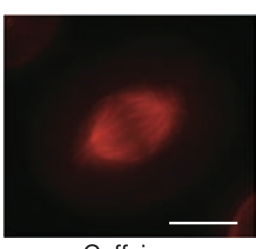

+ Caffeine

$\mathrm{IR}$

Figure 1 Effects of ATM and ATR activation on spindle assembly. (a) Spindle and aster assembly in untreated mitotic CSF extracts, in extracts supplemented with EcoRI $\left(0.25 \mathrm{U} \mathrm{\mu l}^{-1}\right), E c o R I$ and Ku55933 $(20 \mu \mathrm{M})$ or EcoRI and caffeine ( $2 \mathrm{mM})$. Extracts were supplemented with rhodaminetubulin to stain microtubules (red). DNA was stained with DAPI (blue). Scale bars, $10 \mu \mathrm{m}$. (b) Quantification of DNA-associated microtubule structures in extracts treated as indicated. Percentage of bipolar spindles, abnormal spindles (spindles without poles and spindles with dispersed chromosomes), asters and aggregates, is shown after counting 100 structures for each treatement. The images and the graph represent a typical finding. (c) Spindle

of recombinant Plx1 could not rescue spindle defects (Supplementary Information, Fig. S2a). Spindle assembly requires generation of GTPbound Ran (Ran-GTP) ${ }^{10}$. However, although constitutively active recombinant Ran-GTP $\left(\operatorname{Ran}^{\mathrm{Q} 69 \mathrm{~L}}\right)^{10}$ induced spindle-like structures in the presence of active ATM and ATR, it did not restore full spindle assembly (Supplementary Information, Fig. S2b). To uncover the spindle assembly pathway targeted by ATM and ATR, we tested whether ATM and ATR affected the formation of anastral spindles, which can be found in meiotic cells and can be formed in vitro in the presence of chromatin beads made with linear DNA molecules in the absence of aster-centrosome structures ${ }^{11}$. Interestingly, although chromatin beads induced ATM and ATR activation (Fig. 2c), as expected by the b

$\square$ Spindle $\square$ Abnormal spindle $\square$ Aster $\square$ Aggregate

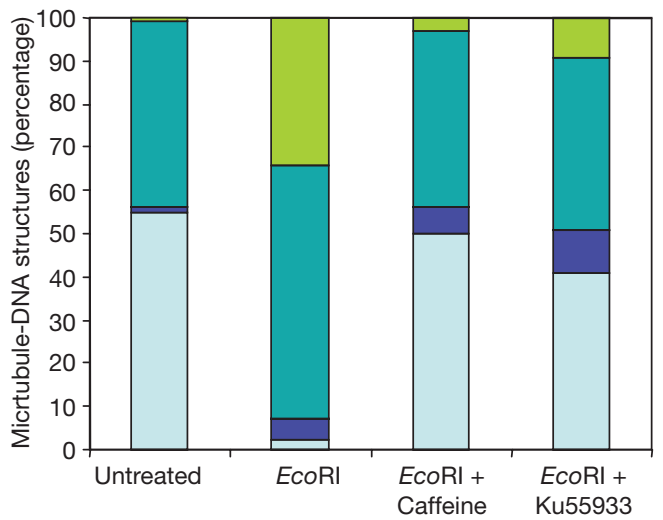

d

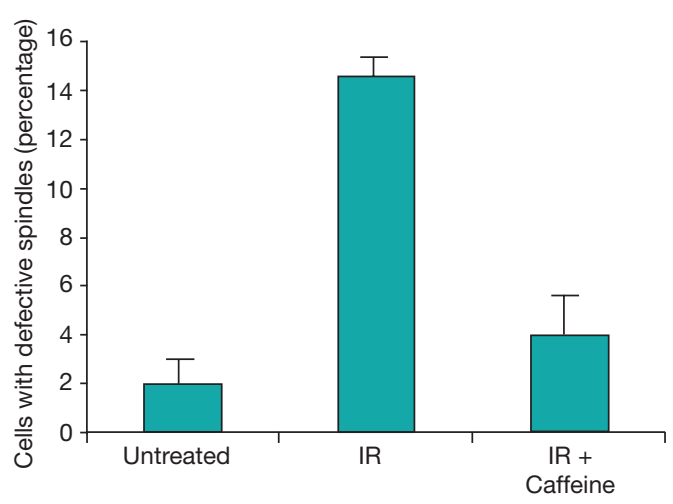

assembly in XTC cells that were synchronized in mitosis with MG132 (25 $\mu \mathrm{M})$ following an S-phase arrest obtained with a double thymidine block. Cells were untreated or irradiated with 10 Gys (IR) as they entered mitosis $8 \mathrm{~h}$ after thymidine release in the absence or presence of caffeine $(5 \mathrm{mM})$. Cells were collected and processed for immunostaining with anti $\alpha$-tubulin and anti histone $\mathrm{H} 3$ phospho-Ser 10 (pS10H3) antibodies. Scale bars, $10 \mu \mathrm{m}$. (d) Quantification of experiments in c showing the percentage of mitotic cells with defective spindles (200 cells counted for each sample). Data are mean \pm s.d. of three independent experiments; ${ }^{*} P<0.05$, compared with untreated and IR + caffeine-treated samples, $t$-test.

presence of linear DNA molecules, anastral spindle formation was normal (Fig. 2d), consistent with previous observations ${ }^{11}$. This indicates that the DNA damage response only inhibits spindle assembly induced by sperm nuclei. As anastral spindle assembly depends on many of the pathways required for aster-centrosome-driven somatic spindles ${ }^{12}$, we could further exclude a role of ATM and ATR in their regulation. Centrioles associated with sperm nuclei promote the formation of aster-centrosome structures, acting as dominant sites for spindle assembly ${ }^{13}$. Inhibition of aster-centrosome-dependent spindle formation and perturbed aster maturation suggested that ATM and ATR targets responsible for this effect were linked to the aster-centrosome-dependent spindle assembly pathway. 

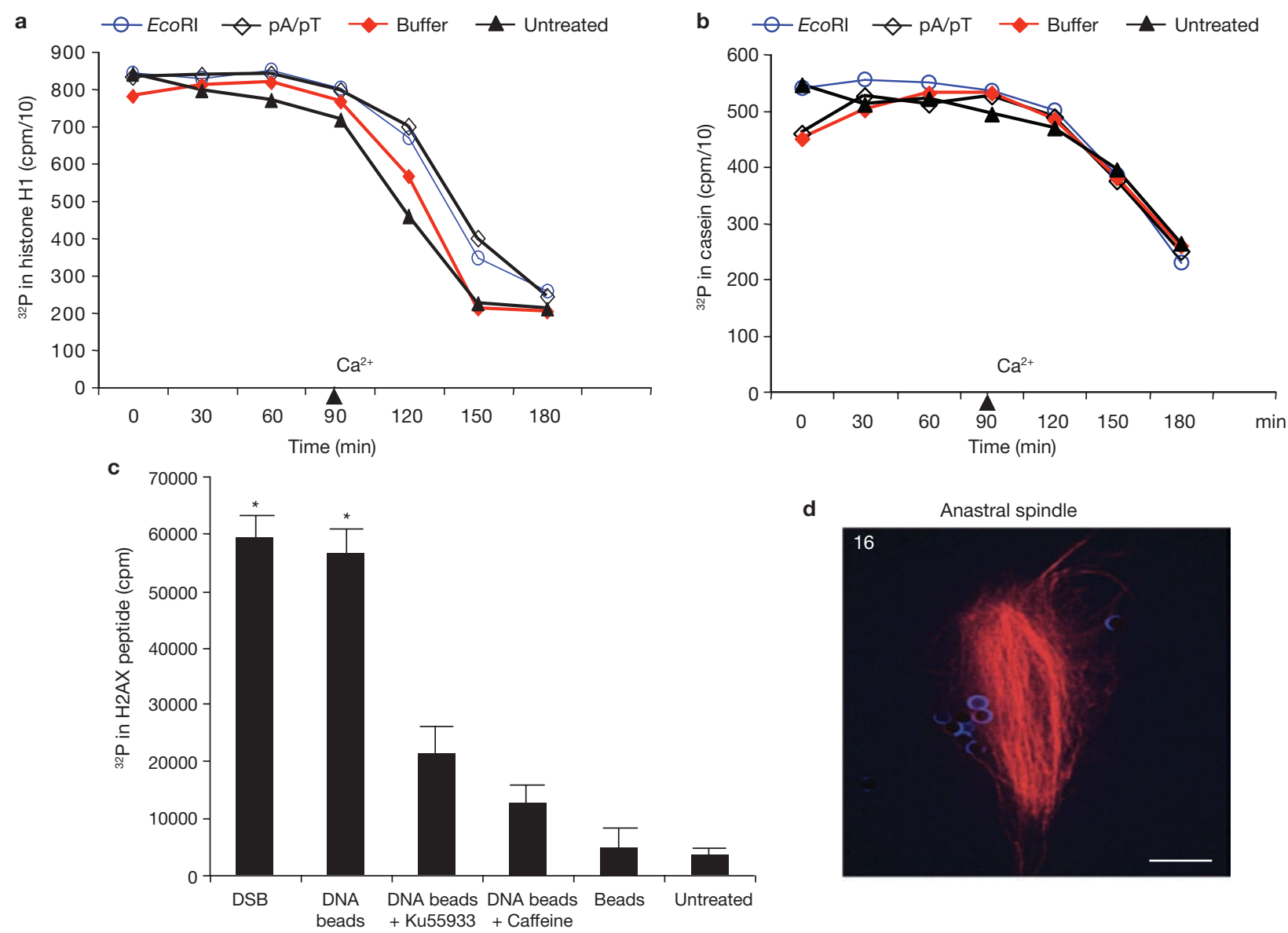

Figure 2 Effects of ATM and ATR activation on mitotic kinases and anastral spindles. (a, b) Cdk1 (a) and PIx1 (b) activities measured in mitotic CSF extracts supplemented with sperm nuclei and EcoRI $\left(25 \mathrm{U} \mathrm{ul}^{-1}\right.$ ), linear DNA (pA/pT), buffer or left untreated. $\mathrm{Ca}^{2+}$ was added after 90 min incubation at $23^{\circ} \mathrm{C}$ to induce mitosis exit. Data are mean of 3 experiments. (c) ATM and ATR kinase activity in extracts used for anastral spindle assembly (see Supplementary Information, Methods,

To identify ATM and ATR targets, we developed a screening strategy using a cDNA expression library ${ }^{14}$ (Fig. 3a). Pools of Xenopus cDNAs were translated in reticulocyte lysates in the presence of ${ }^{35} \mathrm{~S}$-methionine and mixed with egg extracts that were untreated or supplemented with linear DNA. ${ }^{35}$ S-labelled proteins were then separated on SDS-PAGE and differences in migration patterns were monitored. Activation of ATM and ATR caused the appearance of slower-migrating forms of ${ }^{35}$ S-labelled proteins (Supplementary Information, Fig. S2c) resulting from phosphorylation by active ATM and ATR or by other DSBactivated kinases. ATM and ATR inhibitors were used to identify targets whose shift was selectively abolished (Fig. 3a, c). In contrast to other procedures based on direct in vitro phosphorylation with recombinant proteins, this protocol allows the identification of kinase targets in the physiological context of egg extract. Few translated clones shifted in egg extract, indicating that the assay is specific (Supplementary Information, Fig. S2c). Among these, the Xenopus orthologue of centrosomal protein CEP63 (XCEP63; ref. 15) was the most likely to be involved in centrosome-dependent spindle assembly (Fig. 3b; Supplementary Information, Fig. S2d). XCEP63 is conserved among vertebrates and contains a large domain present in the SMC (structural maintenance
$\mathrm{H} 2 \mathrm{AX}$ kinase assay) in the presence of linear plasmid (DSB, $5 \mathrm{ng} \mathrm{l}^{-1}$ ),

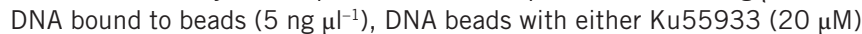
or caffeine $(2 \mathrm{mM})$, beads alone or untreated. Data are mean \pm s.d. of three independent experiments; $P<0.001$, compared with untreated and caffeine- or Ku55933-treated samples, $t$-test. (d) Spindle formed by chromatin beads (Anastral spindle). The average number of spindles $\times$ field is indicated in the corner. Scale bar, $10 \mu \mathrm{m}$.

of chromosomes) protein family (Fig. 3b; Supplementary Information, Fig. S2d). Translated XCEP63 underwent a caffeine-sensitive molecular weight shift in egg extract supplemented with linear DNA (Fig. 3c). Endogenous XCEP63 was phosphorylated in the presence of active ATM and ATR and this phosphorylation was abolished by phosphatase treatment (Fig. 3d). Recombinant XCEP63 fused to maltose binding protein (MBP) incubated in egg extract was also extensively phosphorylated after activation of ATM and ATR, resulting in a molecular weight shift (Supplementary Information, Fig. S3a). Using mass spectrometry, we identified Ser 560 as the main ATM and ATR phosphorylation site (Supplementary Information, Fig. S3a-d). ATM and ATR phosphorylate XCEP63 Ser 560 in vitro and Ser 560 to Ala substitution (XCEP63 ${ }^{\mathrm{S560A}}$ ) abolished this phosphorylation (Supplementary Information, Fig. S4a). Interestingly, Ser 560 is followed by Leu and Glu residues (SLE) instead of the more frequent Gln and Glu (SQE; Fig. 3b) ${ }^{9}$. XCEP63 $3^{\mathrm{S560A}}$ mutation suppressed the XCEP63 shift induced by ATM and ATR (Fig. 3e). Antibodies directed against phosphorylated Ser 560 of XCEP63 specifically detected phosphorylated forms of recombinant and endogenous XCEP63 in egg extract containing active ATM and ATR (Fig. 3f). This phosphorylation was abolished by ATM and ATR inhibitors (Fig. 3g) 

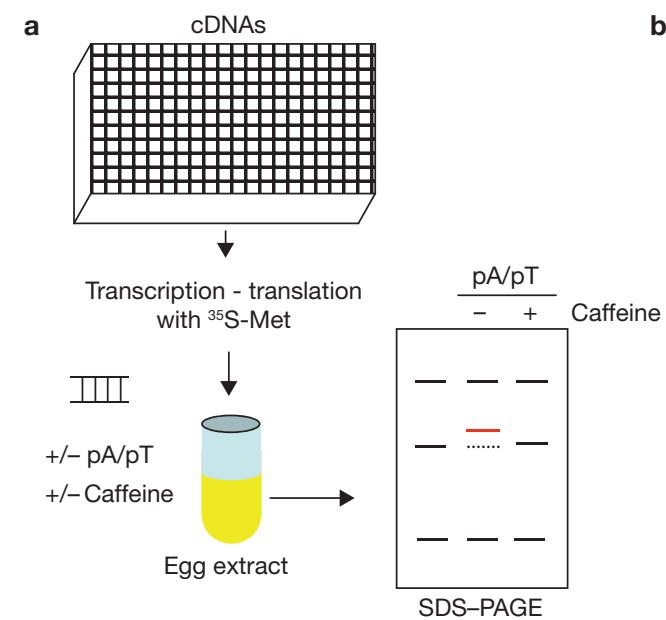

f

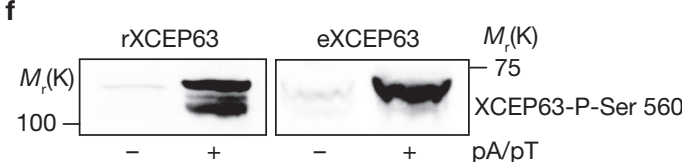

g
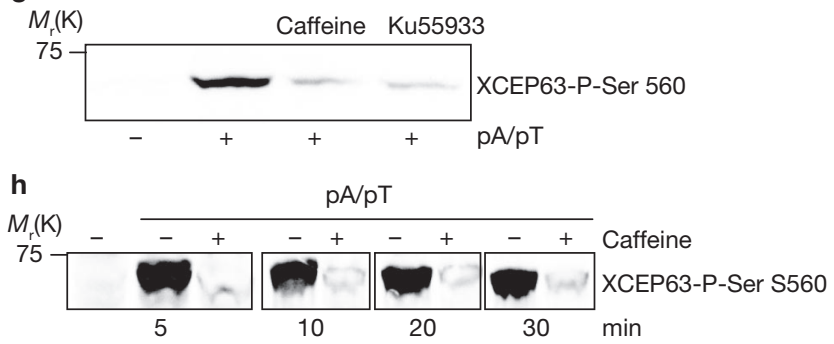

Figure 3 Identification and characterization of the ATM and ATR target XCEP63. (a) Xenopus cDNAs transcribed and translated in reticulocyte lysates in the presence of ${ }^{35} \mathrm{~S}$-methionine were mixed with egg extracts that were untreated, treated with linear DNA (pA/pT) with $(+)$ or without $(-)$ caffeine $(2 \mathrm{mM})$ and run on SDS-PAGE. Differences in migration patterns (red) following ATM and ATR activation were monitored. (b) Structure of XCEP63 with an SMC domain found in proteins involved in chromosome segregation and the ATM and ATR phosphorylated motif. (c) ${ }^{35}$ S-XCEP63 in extracts that were untreated or supplemented with $\mathrm{pA} / \mathrm{pT}$ with $(+)$ or without (-) caffeine. (d) Molecular weight shift of endogenous XCEP63 in extracts supplemented with (+) or without $(-)$ pA/pT after treatment with $\lambda$ phosphatase buffer or $\lambda$ phosphatase. The asterisk indicates a nonspecific band. (e) Translated ${ }^{35}$ S-XCEP63 (WT) and Ser 560 to Ala mutant (S560A) in extracts with (+) or without (-) pA/pT. (f) Western blot using anti

or by phosphatase treatment (Supplementary Information, Fig. S4b). Ser 560 phosphorylation was also induced by sperm nuclei treated with EcoRI (Supplementary Information, Fig. S4b) and could be detected as early as $5 \mathrm{~min}$ after addition of DSBs (Fig. 3h). We confirmed that XCEP63 localizes to spindle poles and centrosomes in egg extract and in Xenopus XTC cells using antibodies against XCEP63 and XCEP63 fused to green fluorescent protein (GFP) (Fig. 3i; Supplementary Information, Fig. S4d). Looking for possible effects of CEP63 phosphorylation, we found that activation of ATM and ATR induced XCEP63 displacement from spindle poles and centrosomes. Under these conditions, XCEP63 could be detected outside aster-centrosomes, seen as diffused staining on defective spindles and DNA-microtubule aggregates assembled in the
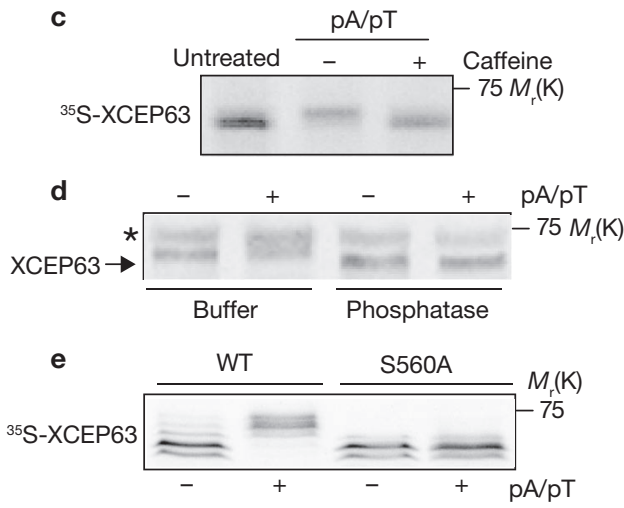

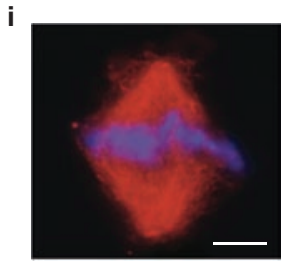

$\gamma$-Tubulin

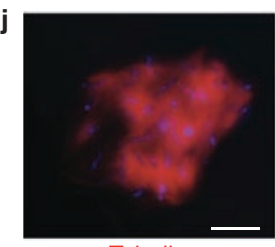

$\alpha-$ Tubulin

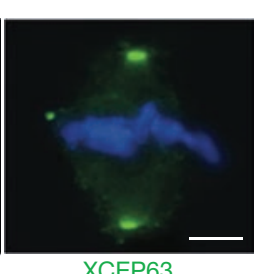

XCEP63

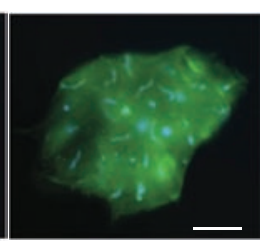

XCEP63
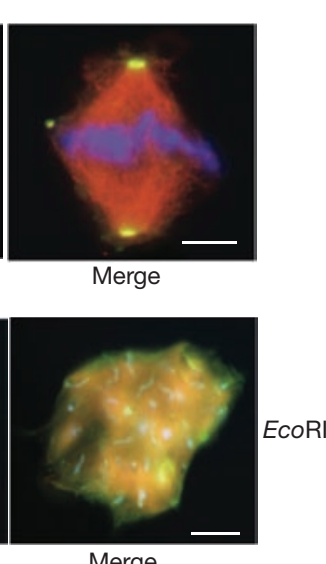

Merge
phospho-Ser 560-XCEP63 antibodies (XCEP63-P-Ser 560) performed on egg extract to detect phosphorylation of Ser 560 of endogenous XCEP63 (eXCEP63) or of recombinant maltose-binding-protein (MBP) fused to XCEP63 (rXCEP63) added to egg extract. Extracts were treated with $(+)$ or without (-) pA/pT. (g) Western blot using anti phospho-Ser 560XCEP63 antibodies performed on egg extract with $(+)$ or without $(-)$ pA/ pT and caffeine $(2 \mathrm{mM})$ or Ku55933 $(20 \mu \mathrm{M})$. (h) Western blot using anti phospho-Ser 560-XCEP63 antibodies performed on egg extract with (+) or without (-) pA/pT and caffeine. Samples of egg extract were collected at the indicated times after DNA addition. (i) Immunofluorescence with anti $\gamma$-tubulin and anti-XCEP63 antibodies on spindle assembly in egg extract. Scale bars, $10 \mu \mathrm{m}$. (j) Immunofluorescence with anti $\alpha$-tubulin and antiXCEP63 antibodies on spindle assembly in egg extract supplemented with EcoRI. Scale bars, $10 \mu \mathrm{m}$.

extract (Fig. 3j; Supplementary Information, Fig. S4e). Similar results were obtained in XTC cells after induction of chromosomal breakage induced by the topoisomerase I inhibitor camptothecin (Supplementary Information, Fig. S4f). Caffeine treatment prevented centrosome displacement of XCEP63 (Supplementary Information, Fig. S4e, f).

To determine the role of XCEP63 in spindle assembly, we depleted XCEP63 from egg extract (Supplementary Information, Fig. S4c). XCEP63 depletion inhibited spindle assembly and induced formation of DNA-associated microtubule aggregates (Fig. 4a). Recombinant XCEP63 restored normal spindle assembly in XCEP63-depleted extracts (Fig. 4a, b). To test whether Ser 560 phosphorylation could affect XCEP63-mediated spindle assembly in extracts containing active ATM 
a Untreated
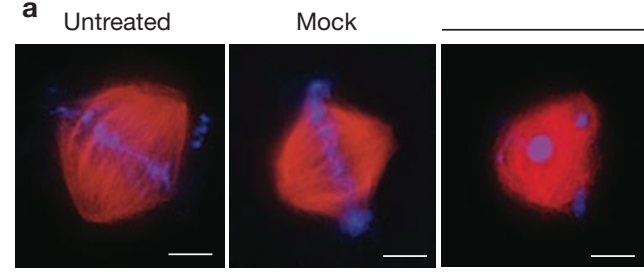

XCEP63-depleted

c

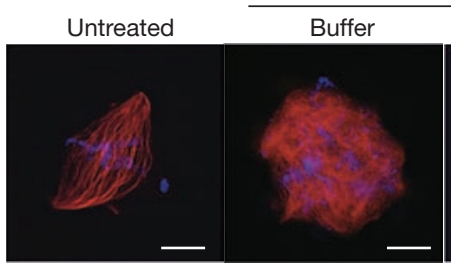

ECOR
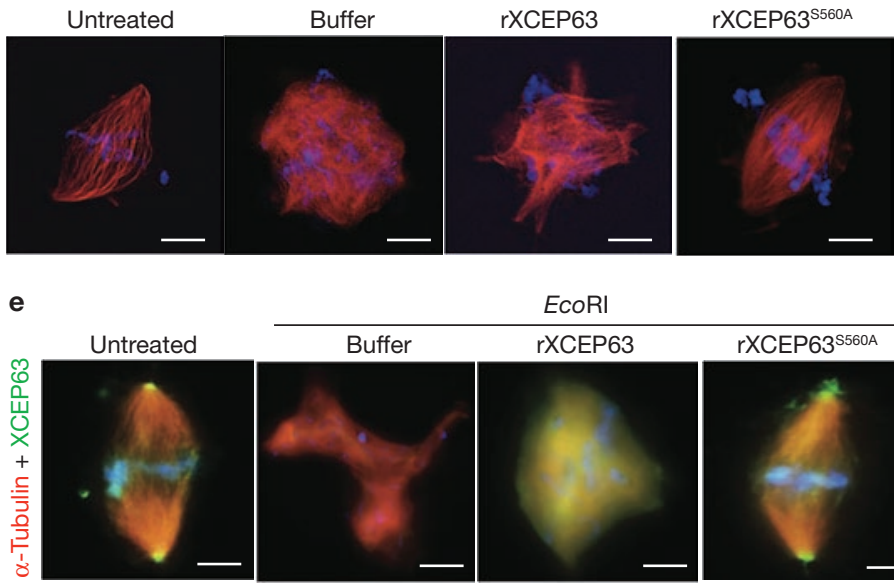

EcoRI

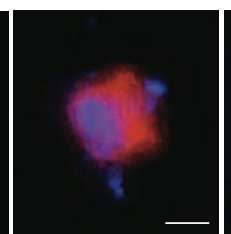

Buffer rXCEP63 rXCEP63 $3560 \mathrm{~A}$

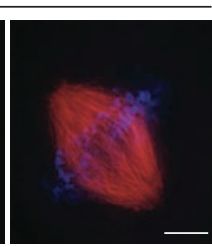

rXCEP63
Figure 4 The function of XCEP63 in spindle assembly and in the ATM- and ATR-dependent checkpoint. (a) Spindle assembly in untreated, mock or XCEP63-depleted extracts supplemented with buffer or recombinant XCEP63 ( $r X C E P 63,50 \mathrm{ng}^{\mathrm{l}} \mathrm{l}^{-1}$ ). Scale bars, $10 \mu \mathrm{m}$. (b) Quantification of DNAassociated microtubule structures obtained under the conditions indicated in a. Percentage of microtubule-DNA structures is shown and 100 structures were counted for each treatement. (c) Spindle assembly in untreated extracts or XCEP63-depleted extracts supplemented with EcoRI in the presence of

and ATR, we replaced endogenous XCEP63 with XCEP63 ${ }^{\mathrm{S560A}}$, a recombinant form that cannot be phosphorylated. In contrast to wild-type $\mathrm{XCEP} 63, \mathrm{XCEP} 63^{\mathrm{S560A}}$ rendered spindle assembly insensitive to ATM and ATR, restoring the formation of normal spindles (Fig. 4c, d). XCEP63 ${ }^{\mathrm{S} 560 \mathrm{~A}}$ was also resistant to displacement from spindle poles induced by ATM and ATR (Fig. 4e). These data suggest that ATM- and ATR-dependent Ser 560 phosphorylation promotes XCEP63 delocalization from astercentrosomes, inactivating XCEP63-dependent spindle assembly in the presence of chromosomal breakage. The role of XCEP63 is restricted to mitosis as XCEP63 depletion did not affect DNA replication or its inhibition following chromosomal breakage in egg extract ${ }^{4}$ (Supplementary Information, Fig. 4g). To test whether CEP63 has similar roles in other vertebrate organisms, we isolated the avian CEP63 orthologue (Fig. 5a) and studied its mitotic function in the genetically modifiable chicken DT40 cells ${ }^{16}$. Using CEP63-GFP, we confirmed that CEP63 localizes to centrosomes and spindle poles in these cells (Fig. 5b). Similarly to Xenopus, avian CEP63 was displaced from spindle poles in mitotic DT40 cells (Fig. 5b) following camptothecin-induced chromosomal breakage (Supplementary Information, Fig. S5a). The displacement of CEP63 was detected immediately after DNA damage and therefore was unlikely to be due to centrosome amplification, which requires longer incubation times ${ }^{17,18}$. Alteration in the distribution pattern of CEP63 was suppressed by caffeine, indicating that CEP63 in DT40 cells is also under the control of ATM and ATR (Fig. 5b and 5c). As DT40 cells allow efficient gene targeting we inactivated the CEP63 gene to verify its role in mitosis and b $\square$ Spindle $\square$ Abnormal spindle $\square$ Aster $\square$ Aggregate

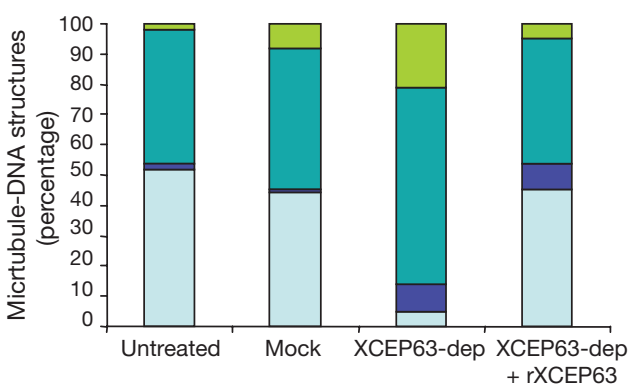

d $\square$ Spindle $\square$ Abnormal spindle $\square$ Aster $\square$ Aggregate

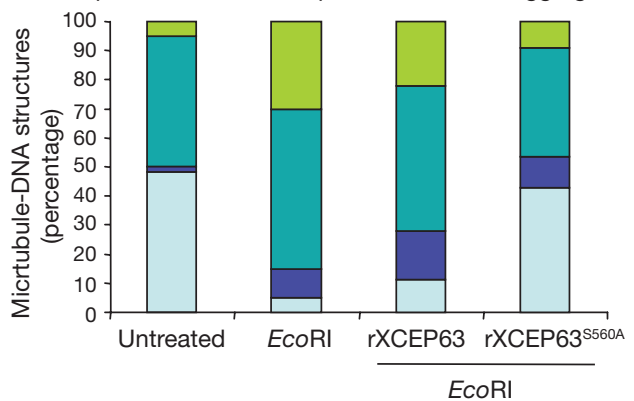

buffer, rXCEP63 (50 ng $\mu^{-1}$ ) or Ser 560 to Ala mutant XCEP63 (rXCEP63 ${ }^{\text {S560A, }}$

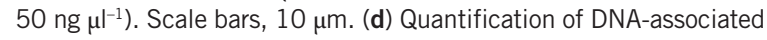
microtubule structures obtained under the conditions indicated in c. Percentage of microtubule-DNA structures is shown and 100 structures were counted for each treatement. (e) Immunofluorescence using anti $\alpha$-tubulin and anti-XCEP63 antibodies on spindles assembled in untreated extracts or XCEP63-depleted extracts supplemented with EcoRI in the presence of buffer,

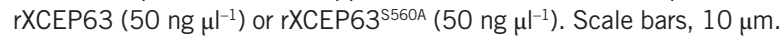

spindle assembly. We obtained several clones in which the CEP63 locus was successfully targeted, leading to the disappearance of CEP63 mRNA and protein (Fig. 5d-g). CEP63-/- cells had extremely slow growth kinetics. A proliferation curve showed severe impairment in the cell duplication rate, compared with $C E P 63^{+/+}$cells (Fig. 5h). Similar results were obtained with three different $C E P 63^{-1-}$ clones (data not shown). Cell-cycle analysis showed an increase in the G2/M population for $\mathrm{CEP}_{63^{-/-}}$cells (Supplementary Information, Fig. S5b-d). The presence of a sub-G1 peak indicated the occurrence of apoptosis in $C E P 63^{-/-}$cells (Supplementary Information, Fig. S5b, c) confirmed by their decreased survival over time (Supplementary Information, Fig. S5e). As XCEP63 is required for normal spindle assembly, we monitored spindle formation in $\mathrm{CEP}_{63^{-/-}}$cells. After release from nocodazole arrest, $\mathrm{CEP} 63^{-/-}$cells were unable to assemble normal spindles and accumulated in prophase (Fig. 5i; Supplementary Information, Fig. S5f). However, in contrast to Xenopus, spindle formation, which was abolished in the early stages of mitosis, eventually recovered. In turn, $C E P 63^{-/-}$cells formed abnormal, disorganized and multipolar spindles with chromosomes not attached to microtubules or unequally segregated, and with hypercondensed apoptotic nuclei (Fig. 5i; Supplementary Information, Fig. S5g). Spindle recovery in $\mathrm{CEP}^{-3^{--}}$cells may depend on centrosome-independent reorganization of spindle poles ${ }^{19}$, relying on structural rearrangement of the cytoskeleton or mitosis progression events that are missing in permanently arrested mitotic egg-cell-free extracts. Consistent with delayed and abnormal spindle formation, mitosis progression in $\mathrm{CEP}^{-/-}$cells 


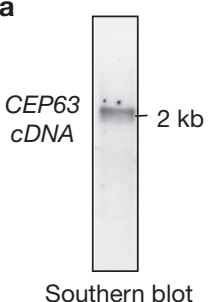

b

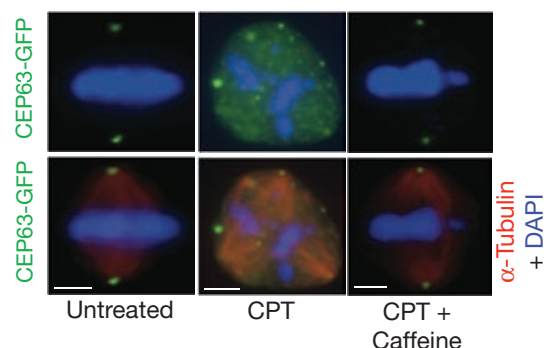

d

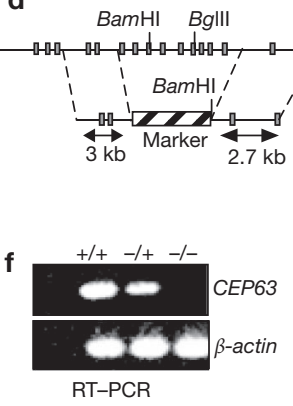

j

$$
\begin{aligned}
& \downarrow \mathrm{CEP}_{63}^{+/+} \rightarrow \mathrm{CEP} 63^{+/+} \mathrm{IR} \\
& \square \mathrm{CEP} 63^{-/-}+\mathrm{CEP} 63^{+/+} \text {IR Caffeine }
\end{aligned}
$$

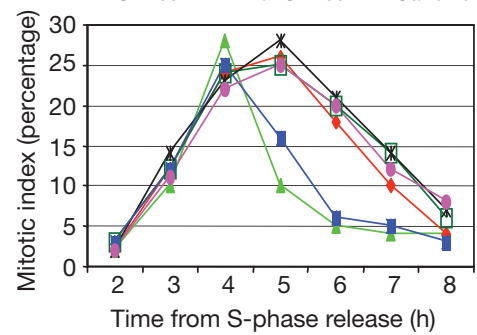

Time from S-phase release (h) h

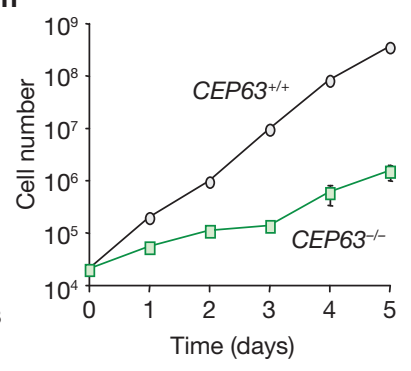

IR +

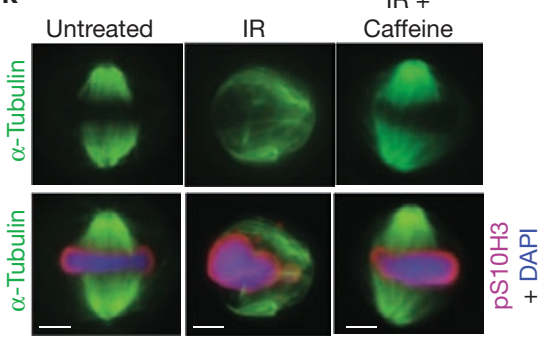

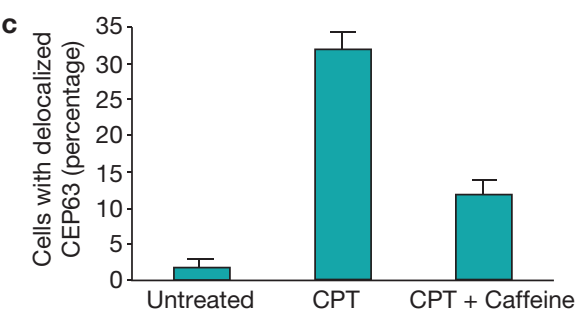

Prophase Metaphase Anaphase Interphase/
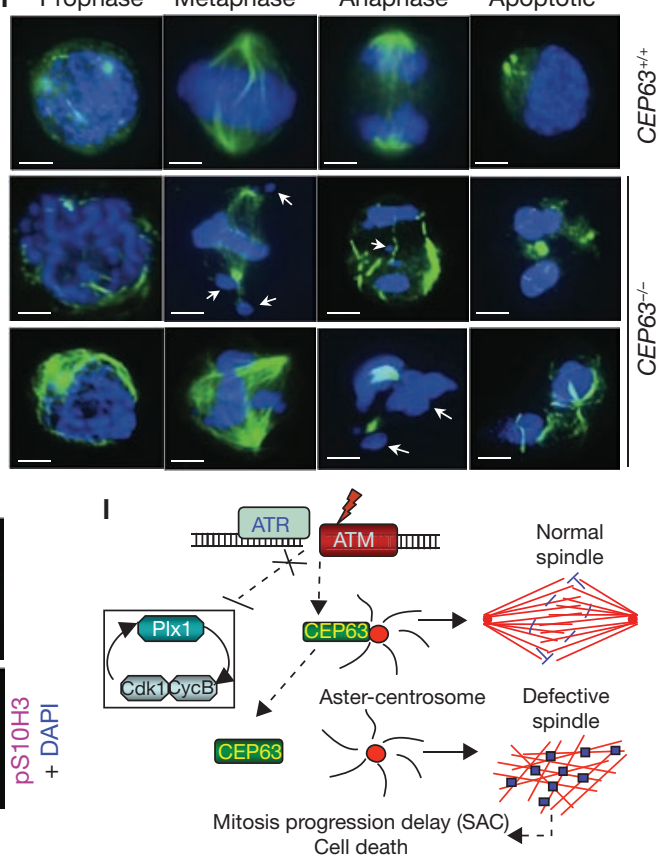

Figure 5 Characterization of CEP63 in DT40 cells. (a) Southern blot showing chicken CEP63 cDNA obtained from RT-PCR of mRNA isolated from DT40 cells. (b) Localization of CEP63-GFP fusion protein in mitotic DT40 cells stably transfected with CEP63-GFP that were untreated, incubated with camptothecin (CPT, $1 \mu \mathrm{M})$ or CPT $(1 \mu \mathrm{M})$ and caffeine $(5 \mathrm{mM})$. Cells were stained with anti $\alpha$-tubulin antibodies as indicated. Scale bars, $5 \mu \mathrm{m}$. (c) Percentage of cells with altered CEP63 staining. Cells were untreated, incubated with CPT $(1 \mu \mathrm{M})$ or CPT $(1 \mu \mathrm{M})$ and caffeine $(5 \mathrm{mM})$ as indicated. Data are mean \pm s.d. of three independent experiments; ${ }^{*} P<0.05$, compared with untreated and CPT + caffeinetreated samples, $t$-test. (d) Chicken CEP63 genomic locus and the genetargeting strategy. (e) Southern blot of chicken DT40 genomic DNA from heterozygous $(-/+)$ and homozygous (-I-) mutant CEP63 cells digested with $B a m H 1$ and $B g / l l$ using the genomic DNA fragment shown in $\mathbf{d}$ as a probe. (f) RT-PCR of chicken DT40 mRNA using primers specific for

was slower (Fig. 5j). To verify the role of CEP63 in the control of mitosis following chromosomal breakage, we monitored mitosis progression of CEP63 $3^{+/+}$and $C E P 63^{-/-}$cells treated with IR during early mitotic stages after release from a thymidine-induced S-phase block. In these experiments we observed a transient delay in mitotic progression in $C E P 63^{+/+}$ cells treated with IR, which was absent in CEP63 ${ }^{-1-}$ cells (Fig. 5j). This delay was accompanied by inhibition of spindle assembly in a fraction of cells and was abolished by caffeine, indicating that it was dependent on ATM and ATR (Fig. 5j, k). As in Xenopus, we found that DNA damage induced caffeine-sensitive phosphorylation of CEP63 immunoprecipitated from DT40 cells following IR treatment (Supplementary Information, Fig. S5h, i). This suggests that avian CEP63 is under the
CEP63 and $\beta$-actin. (g) Western blot of wild type $(+/+)$ and homozygous $(-/-)$ mutant CEP63 cells using anti-chicken CEP63 antibodies. (h) Growth rate of $C E P 63^{+/+}$and $C E P 63^{-/}$cells determined at the indicated times after seeding. Data are mean \pm s.d. of three independent experiments. (i) Spindle assembly and chromosome segregation following release from nocodazole block of $C E P 63^{+/+}$and $C E P 63^{-/-}$cells taken at the indicated mitotic stages. Arrows indicate chromosomes detached from spindle. Cells were stained with anti $\alpha$-tubulin antibodies. Scale bars, $5 \mu \mathrm{m}$. (j) Mitotic index of CEP $63^{+/+}$and $C E P 63^{--}$cells at the indicated times following release from thymidine-induced S-phase arrest. Cells were untreated or irradiated with 10 Gys (IR), with or without caffeine $(5 \mathrm{mM})$ in the early stages of mitosis, $2 \mathrm{~h}$ after release from S-phase arrest. (k) Immunofluorescence with anti a-tubulin and histone $\mathrm{H} 3$ phospho-Ser $10(\mathrm{pS} 1 \mathrm{OH} 3)$ antibodies of $C E P 63^{+/+}$ cells treated as in j. Scale bars, $5 \mu \mathrm{m}$. (I) Proposed model for ATM and ATR mediated control of centrosome dependent spindle assembly.

control of ATM and ATR or other DNA-damage-activated kinases, such as Chk1 or Chk2, although Ser 560 is not conserved (Supplementary Information, Fig. S2d).

We have shown that chromosomal breakage induces ATM- and ATRmediated inactivation of centrosome-dependent spindle assembly in vertebrate model systems that recapitulate DNA damage checkpoints ${ }^{3,4,20}$, centrosome biology $y^{17,18,21}$ and spindle formation ${ }^{2,11,13,22}$. This pathway operates during early mitotic stages and does not affect the activity of major mitotic kinases. Instead, it induces phosphorylation and centrosome displacement of CEP63, inhibiting spindle formation (Fig. 5l). This leads to a transient delay in mitosis progression, probably induced by activation of the spindle assembly checkpoint (SAC), without causing the durable 
mitotic arrest observed after inhibition of chromosome decatenation ${ }^{23}$. This pathway may monitor chromosome breaks that escape the G2/M checkpoint, and facilitate their repair following ATM-dependent chromatin decondensation at the breakage site ${ }^{24}$ without inducing downregulation of mitotic kinases and therefore premature mitosis exit. Alternatively, persistent activation of ATM and ATR due to a high number of unrepaired DSBs in mitosis could trigger cell death. The response to chromosome breakage in mitotic cells varies, depending on the timing and the amount of DNA damage ${ }^{25}$. Abnormal centrosomes and centrosome-independent spindle assembly pathways, which we show to be insensitive to ATM and ATR, may contribute to the complexity of mitotic DNA damage response in vertebrate cells under different conditions.

ATM- and ATR-mediated control of CEP63-dependent centrosome functions could be relevant in preventing genome instability and cellular transformation, a process in which centrosomes have an important role $^{26}$. Interestingly, other centrosome proteins, such as pericentrin, are required for the ATR-dependent checkpoint ${ }^{27}$. Human CEP63 transcript is downregulated in invasive bladder tumours ${ }^{28}$, indicating that loss of CEP63 may contribute to the occurrence of genome instability typical of aggressive human cancers. In Xenopus, XCEP63 coordinates centrosome-dependent assembly of spindle structures. Human CEP63 interacts with DISC1 (ref. 29), a centrosome-associated protein mutated in hereditary schizophrenia and essential for organization of centrosomal dynein $^{30}$. This interaction may be relevant for the function of dynein in centrosome-dependent spindle assembly.

\section{METHODS}

Spindle assembly. CSF extract and sperm nuclei were prepared from Xenopus eggs and testis as described previously ${ }^{2}$. Spindle assembly was monitored by fluorescence microscopy. Briefly, nuclei $\left(1000 \mathrm{\mu l}^{-1}\right)$ were incubated in $20 \mu \mathrm{l} \mathrm{CSF}$-arrested extract containing rhodamine-labelled tubulin $\left(50 \mu \mathrm{g} \mathrm{ml}^{-1}\right.$; Cytoskeleton) for $90 \mathrm{~min}$ at $20^{\circ} \mathrm{C}$. For analysis of samples, reactions were transferred to a $5-\mathrm{ml}$ tube with $1 \mathrm{ml}$ of dilution buffer prepared in $1 \times B R B 80(1 \mathrm{mM} \mathrm{MgCl} 2,1 \mathrm{mM}$ EGTA, $80 \mathrm{mM}$ Pipes, pH6.8) supplemented with $1 \%(\mathrm{v} / \mathrm{v})$ Triton X-100 and 30\% (v/v) glycerol. Fixation buffer ( $1 \mathrm{ml}: 60 \%$ v/v glycerol, 1xMMR, $1 \mathrm{mg} \mathrm{ml}^{-1}$ Hoechst, $10 \%$ formaldehyde from $37 \% \mathrm{w} / \mathrm{v}$ stock) was added and samples were left at room temperature for $5 \mathrm{~min}$. This mixture was layered over $5 \mathrm{ml}$ of cushion solution ( $40 \%$ $\mathrm{v} / \mathrm{v}$ glycerol prepared in $1 \times$ BRB80) in a $15-\mathrm{ml}$ modified Corex tube containing a $12-\mathrm{mm}^{2}$ poly-L-lysine-coated coverslip at the bottom of the tubes. Samples were spun at 16,000 $\mathrm{g}(10,000 \mathrm{rpm}$ using an $\mathrm{HB}-4$ rotor) for $15 \mathrm{~min}$. The coverslips were removed and post-fixed in methanol at $-20^{\circ} \mathrm{C}$. The coverslips were washed with PBS and stained with the primary and secondary antibodies (see Supplementary Information Methods, Immunofluorescence) or placed directly upside down on a drop of mounting medium on a slide and sealed with nail polish.

Spindle assembly in the presence of active ATM and ATR. Nuclei $\left(1000 \mu \mathrm{l}^{-1}\right)$ were incubated in $20 \mu \mathrm{l} \mathrm{CSF-arrested} \mathrm{extract} \mathrm{containing} \mathrm{rhodamine-labelled} \mathrm{tubu-}$ lin $\left(50 \mu \mathrm{g} \mathrm{ml}^{-1}\right.$; Cytoskeleton) for $90 \mathrm{~min}$ at $20^{\circ} \mathrm{C}$. Extracts were supplemented

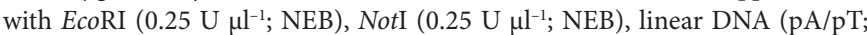

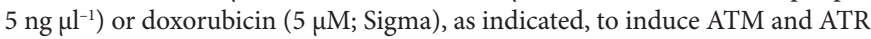
activation. To inhibit ATM and ATR, caffeine (2 mM, Sigma) or Ku55933 (20 $\mu \mathrm{M}$ Calbiochem) were used. CSF-XB buffer (100 mM KCl, $0.1 \mathrm{mM} \mathrm{CaCl}, 10 \mathrm{mM}$ HEPES, pH 7.7, $50 \mathrm{mM}$ sucrose, $5 \mathrm{mM}$ EGTA, $2 \mathrm{mM} \mathrm{MgCl}_{2}$ ) was always used to compensate for volume changes. For bipolar spindles, nuclei $\left(1000 \mu \mathrm{l}^{-1}\right)$ were incubated in $20 \mu \mathrm{l} \mathrm{CSF-arrested} \mathrm{mitotic} \mathrm{egg} \mathrm{extract.} \mathrm{CSF} \mathrm{extracts} \mathrm{were} \mathrm{induced}$ to enter interphase by addition of $\mathrm{CaCl}_{2}$ to a final concentration of $0.4 \mathrm{mM}^{2}$. Cycloheximide $\left(0.2 \mathrm{mg} \mathrm{ml}^{-1}\right)$ was added to the reactions. After a 2-h incubation at $20^{\circ} \mathrm{C}$, an additional half volume of fresh mitotic CSF extract containing rhodamine-labelled tubulin ( $50 \mu \mathrm{g} \mathrm{ml}^{-1}$;Cytoskeleton) was added to generate bipolar spindles. Extracts were then supplemented with CSF-XB buffer, EcoRI $\left(0.25 \mathrm{U} \mathrm{\mu l}^{-1}\right)$ or EcoRI $\left(0.25 \mathrm{U} \mathrm{\mu l}^{-1}\right)$ and caffeine $(2 \mathrm{mM})$. Samples were collected after $60 \mathrm{~min}$ incubation at $20^{\circ} \mathrm{C}$ and processed as described above.
Anastral spindle assembly. Anastral spindles were obtained essentially as described previously ${ }^{14}$. DNA-coated beads or control beads were incubated in CSF extracts that were induced to enter interphase by addition of $\mathrm{CaCl}_{2}$ (final concentration $0.4 \mathrm{mM})^{2}$. Cycloheximide $\left(0.2 \mathrm{mg} \mathrm{ml}^{-1}\right)$ was added to the reactions. After a 2-h incubation at $20^{\circ} \mathrm{C}$, an additional half volume of fresh mitotic CSF extract containing rhodamine-labelled tubulin $\left(50 \mu \mathrm{g} \mathrm{ml}^{-1}\right.$; Cytoskeleton) was added to generate anastral spindles. After an additional $45 \mathrm{~min}$, ATM and ATR activity was monitored by collecting $2-\mu \mathrm{l}$ aliquots and performing histone $\mathrm{H} 2 \mathrm{AX}$ assay in the presence or in the absence of caffeine or Ku55933. The rest of the reaction was processed as described in the previous section on spindle assembly to isolate anastral spindles on coverslips.

cDNA expression library screening. An expression screening method described previously ${ }^{14}$ was adopted with modifications, using a full-length, normalized Xenopus laevis egg cDNA library built in a modified pCS2 expression vector. The library was donated by Tony Hyman (Max Planck Institute of Molecular and Cellular Biology and Genetics, Dresden, Germany). Bacterial cells were transformed with Xenopus cDNA and individually arrayed in 384well plates. Pools of cells corresponding to rows and columns of single plates were grown. Plasmid DNA was prepared from pools using Qiagen miniprep kit and added to an SP6 quick-coupled transcription-translation reticulocyte lysate (TNT, Promega) in the presence of ${ }^{35} \mathrm{~S}$-methionine (Promix, Amersham). After the translation was complete, the ${ }^{35}$ S-labelled lysates $(2 \mu \mathrm{l})$ were added

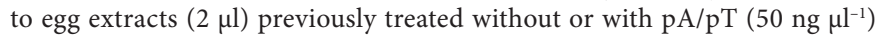
in presence of Ku55933 $(20 \mu \mathrm{M})$ or caffeine $(2 \mathrm{mM})$. Samples were run on a $10 \%$ SDS-PAGE. Proteins were identified by isolating their corresponding cDNA by intersecting pools from rows and columns of the plate. XCEP63 cDNA sequence (GenBank accession number: FJ464988) was determined by sequencing both strands.

Chromosomal damage and linear DNA. To induce chromosomal breakage, CSF extracts were incubated with sperm nuclei $\left(1000 \mu^{l^{-1}}\right)$ and then supplemented with EcoRI $\left(0.25 \mathrm{U} \mathrm{\mu l}^{-1}\right)$ or NotI $\left(0.25 \mathrm{U} \mathrm{\mu l}^{-1}\right)$. To prepare $\mathrm{pA} / \mathrm{pT}$ molecules, 70 -mer poly-deossy-T oligonucleotides were annealed to poly-deossy-A oligonucleotides (Sigma-Genosys) at $16^{\circ} \mathrm{C}$ for $1 \mathrm{~h}$.

Note: Supplementary Information is available on the Nature Cell Biology website.

\section{ACKNOWLEDGEMENTS}

We thank Tim Hunt, members of Clare Hall Laboratories and of the Genome Stability Unit for their comments. We thank H Mahbubani and J Kirk for technical support with Xenopus laevis. This work was funded by Cancer Research UK. V. Costanzo is also supported by the Lister Institute of Preventive Medicine, the European Research Council (ERC) start up grant and the EMBO Young Investigator Program (YIP). A. Vindigni thanks AIRC for its support.

\section{AUTHOR CONTRIBUTIONS}

E.S, D.D. and A.B. performed the experiments and analysed the data in the Xenopus system and in avian DT40 cells; M.H., C.L. and A.V. provided technical and conceptual advice with mass spectrometry; S.T. provided technical and conceptual advice with avian DT40 cells; V.C. planned the experiments and wrote the manuscript.

\section{COMPETING FINANCIAL INTERESTS}

The authors declare no competing financial interests.

Published online at http://www.nature.com/naturecellbiology/ Reprints and permissions information is available online at http://npg.nature.com/ reprintsandpermissions/

1. Maller, J. L. et al. The mechanism of CSF arrest in vertebrate oocytes. Mol. Cell Endocrinol. 187, 173-178 (2002)

2. Desai, A., Murray, A., Mitchison, T. J. \& Walczak, C. E. The use of Xenopus egg extracts to study mitotic spindle assembly and function in vitro. Methods Cell Biol. 61, 385-412 (1999).

3. Costanzo, V., Paull, T., Gottesman, M. \& Gautier, J. Mre11 assembles linear DNA fragments into DNA damage signaling complexes. PLoS Biol. 2, E110 (2004).

4. Yoo, H. Y., Shevchenko, A. \& Dunphy, W. G. Mcm2 is a direct substrate of ATM and ATR during DNA damage and DNA replication checkpoint responses. J. Biol. Chem. 279, 53353-53364 (2004).

5. Hickson, I. et al. Identification and characterization of a novel and specific inhibitor of the ataxia-telangiectasia mutated kinase ATM. Cancer Res. 64, 9152-9159 (2004). 
6. Jazayeri, A. et al. ATM- and cell cycle-dependent regulation of ATR in response to DNA double-strand breaks. Nature Cell Biol. 8, 37-45 (2006).

7. Potapova, T. A. et al. The reversibility of mitotic exit in vertebrate cells. Nature $\mathbf{4 4 0 ,}$ 954-958 (2006)

8. Liu, J. \& Maller, J. L. Xenopus Polo-like kinase PIx1: a multifunctional mitotic kinase. Oncogene 24, 238-247 (2005).

9. Sancar, A., Lindsey-Boltz, L. A., Unsal-Kacmaz, K. \& Linn., S. Molecular mechanisms of mammalian DNA repair and the DNA damage checkpoints. Annu. Rev. Biochem. 73, 39-85 (2004).

10. Carazo-Salas, R. E. et al. Generation of GTP-bound Ran by RCC1 is required for chromatin-induced mitotic spindle formation. Nature 400, 178-181 (1999).

11. Heald, R. et al. Self-organization of microtubules into bipolar spindles around artificial chromosomes in Xenopus egg extracts. Nature 382, 420-425 (1996).

12. Karsenti, E. \& Vernos, I. The mitotic spindle: a self-made machine. Science 294, 543-547 (2001)

13. Heald, R., Tournebize, R., Habermann, A., Karsenti, E. \& Hyman, A. Spindle assembly in Xenopus egg extracts: respective roles of centrosomes and microtubule self-organization. J. Cell Biol. 138, 615-628 (1997).

14. Lustig, K. D. et al. Small pool expression screening: identification of genes involved in cell cycle control, apoptosis, and early development. Methods Enzymol. 283, 83-99 (1997).

15. Andersen, J. S. et al. Proteomic characterization of the human centrosome by protein correlation profiling. Nature 426, 570-574 (2003).

16. Zachos, G. et al. Chk1 is required for spindle checkpoint function. Dev. Cell 12, 247-260 (2007)

17. Matsumoto, Y. \& Maller, J. L. Calcium, calmodulin and CaMKII requirement for initiation of centrosome duplication in Xenopus egg extracts. Science 295, 499-502 (2002).

18. Dodson, $\mathrm{H}$. et al. Centrosome amplification induced by DNA damage occurs during a prolonged G2 phase and involves ATM. EMBO J. 23, 3864-3873 (2004).
19. Khodjakov, A., Cole, R. W., Oakley, B. R. \& Rieder, C. L. Centrosome-independent mitotic spindle formation in vertebrates. Curr. Biol. 10, 59-67 (2000).

20. Zachos, G., Rainey, M. D. \& Gillespie, D. A. Chk1-deficient tumour cells are viable but exhibit multiple checkpoint and survival defects. EMBO J. 22, 713-723 (2003).

21. Matsumoto, Y. \& Maller, J. L. A centrosomal localization signal in cyclin E required for Cdk2-independent S. phase entry. Science 306, 885-888 (2004).

22. Vagnarelli, P. et al. Condensin and Repo-Man-PP1 cooperate in the regulation of chromosome architecture during mitosis. Nature Cell Biol. 8, 1133-1142 (2006).

23. Skoufias, D. A., Lacroix, F. B., Andreassen, P. R., Wilson, L. \& Margolis, R. L. Inhibition of DNA decatenation, but not DNA damage, arrests cells at metaphase. Mol. Cell 15, 977-990 (2004).

24. Goodarzi, A. A. et al. ATM signaling facilitates repair of DNA double-strand breaks associated with heterochromatin. Mol. Cell 31, 167-177 (2008).

25. Morrison, C. \& Rieder, C. L. Chromosome damage and progression into and through mitosis in vertebrates. DNA Repair 3, 1133-1139 (2004)

26. Basto, R. et al. Centrosome amplification can initiate tumorigenesis in flies. Cel/ 133, 1032-1042 (2008)

27. Griffith, E. et al. Mutations in pericentrin cause Seckel syndrome with defective ATRdependent DNA damage signaling. Nature Genet. 40, 232-236 (2008).

28. Buim, M. E., Soares, F. A., Sarkis, A. S. \& Nagai, M. A. The transcripts of SFRP1, CEP63 and EIF4G2 genes are frequently downregulated in transitional cell carcinomas of the bladder. Oncology 69, 445-454 (2005).

29. Morris, J. A., Kandpal, G., Ma, L. \& Austin, C. P. DISC1 (disrupted-in-schizophrenia 1 ) is a centrosome-associated protein that interacts with MAP1A, MIPT3, ATF4/5 and NUDEL: regulation and loss of interaction with mutation. Hum. Mol. Genet. 12, 1591-1608 (2003)

30. Kamiya, A. et al. A schizophrenia-associated mutation of DISC1 perturbs cerebral cortex development. Nature Cell Biol. 7, 1167-1178 (2005). 


\section{cell biology}

DOI: $10.1038 / \mathrm{ncb} 1835$

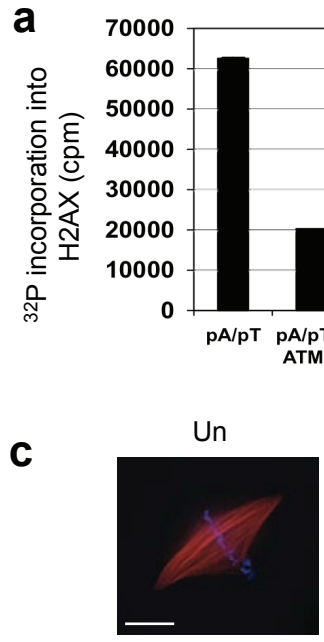

d
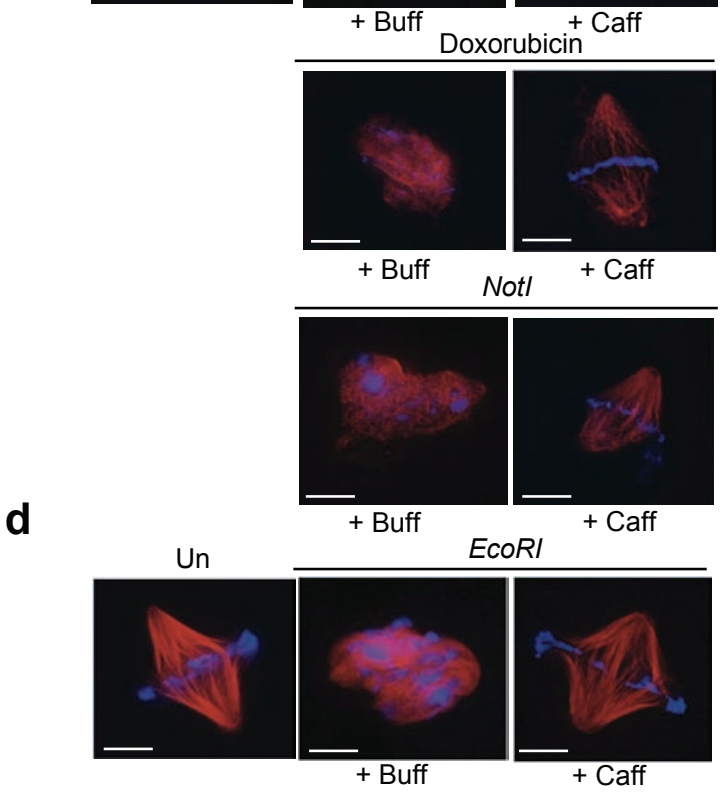
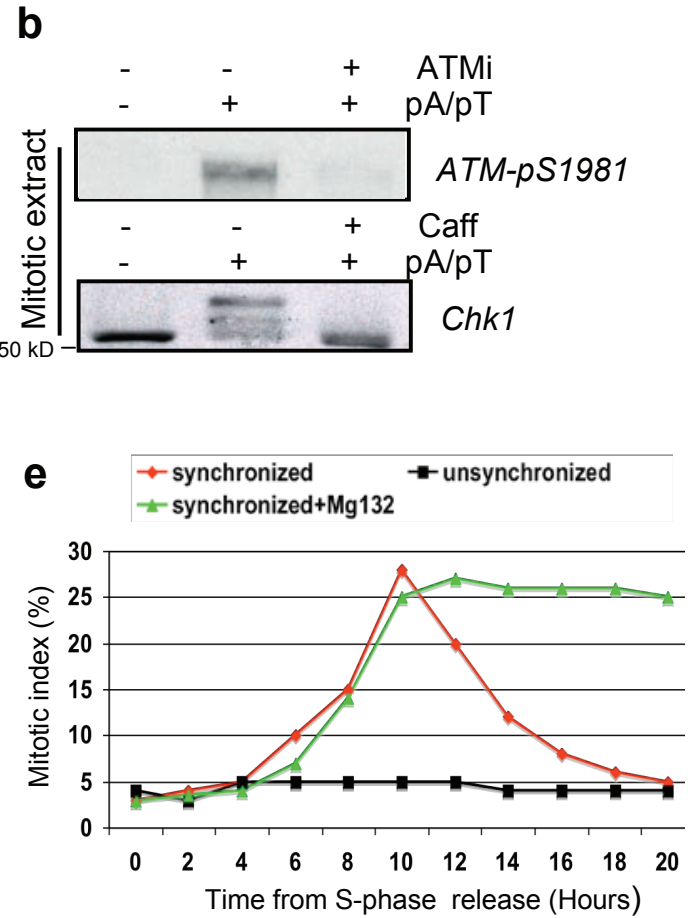

$\mathbf{f}$

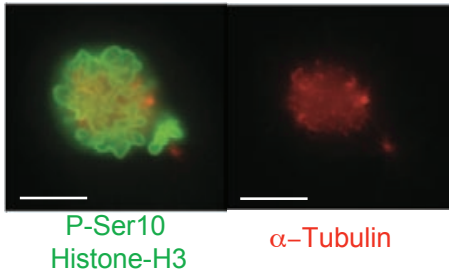

Figure S1 ATM and ATR activation and their effect on spindle assembly. a, Histone $H 2 A X$ carbossi-terminal peptide in vitro kinase assay. CSF egg extracts were treated with $5 \mathrm{ng} / \mu$ l linear DNA (pA/pT), linear DNA and 20 $\mu \mathrm{M} \mathrm{Ku} 55933(\mathrm{pA} / \mathrm{pT}+$ ATMi), linear DNA and $2 \mathrm{mM}$ caffeine (pA/pT + Caff), 1000 sperm nuclei/ $\mu l$ and $0.25 \mathrm{U} / \mu \mathrm{l}$ EcoRI (EcoRI + Sperm), 1000 nuclei and $0.25 \mathrm{U} / \mu \mathrm{l} E c o R /$ in the presence of $20 \mu \mathrm{M} \mathrm{Ku} 55933$ (EcoRI+ Sperm + ATMi), 1000 nuclei/ $\mu$ and $0.25 \mathrm{U} / \mu \mathrm{l} E c 0 R /$ in the presence of 2 $\mathrm{mM}$ caffeine $(E c o R I+$ Sperm + ATMi), with 1000 nuclei/ $\mu$ l only (Sperm) or left untreated (Untreat). b. Western blot using anti ATM phospho-serine 1981 (top panel) and anti Chk1 antibodies (lower panel) of CSF-arrested mitotic egg extract that was untreated, supplemented with $\mathrm{pA} / \mathrm{pT}$ in the presence or in the absence of caffeine (Caff) or Ku55933 (ATMi) as indicated. c, Spindle assembly obtained by incubation for 90 minutes in

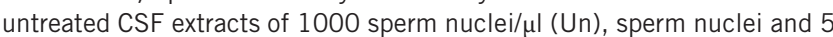
$\mathrm{ng} / \mu \mathrm{l}$ linear DNA molecules (pA/pT), sperm nuclei and $5 \mu \mathrm{M}$ Doxorubicin or sperm nuclei and $0.25 \mathrm{U} / \mu \mathrm{l}$ NotI (Notl). Extracts were supplemented with buffer (Buff) or $2 \mathrm{mM}$ caffeine (+ Caff). The images shown represent a typical finding. Scale bar, $10 \mu \mathrm{m}$. d, Bipolar spindle assembly obtained by incubation for 90 minutes in untreated interphase extracts of 1000 sperm nuclei/ $\mu$ l. Extracts were then supplemented with mitotic CSF arrested extracts in the presence of $0.25 \mathrm{U} / \mu \mathrm{l} E c o R /$ or plus buffer (Buff) or $2 \mathrm{mM}$ Caffeine (Caff). Scale bar, $10 \mu \mathrm{m}$. e, Mitotic index showing XTC cells synchronization obtained by a double-thymidine block following by release in normal medium in the presence or in the absence of $25 \mu \mathrm{M}$ MG132 as indicated. Mitotic index was obtained by counting the relative number of mitotic cells spun on coverslip and stained with anti $\alpha$-tubulin and anti phosphorylated serine 10 of histone $\mathrm{H} 3$ antibodies (see Methods). f, Additional images of cells irradiated at the early stages of mitosis and stained with anti phospho serine 10 of histone $\mathrm{H} 3$ and $\alpha$-tubulin as shown in Fig 1c. Scale bar, $10 \mu \mathrm{m}$. 

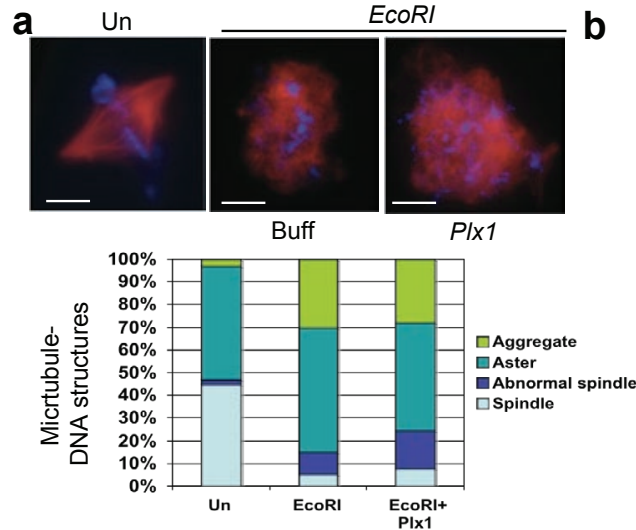

C

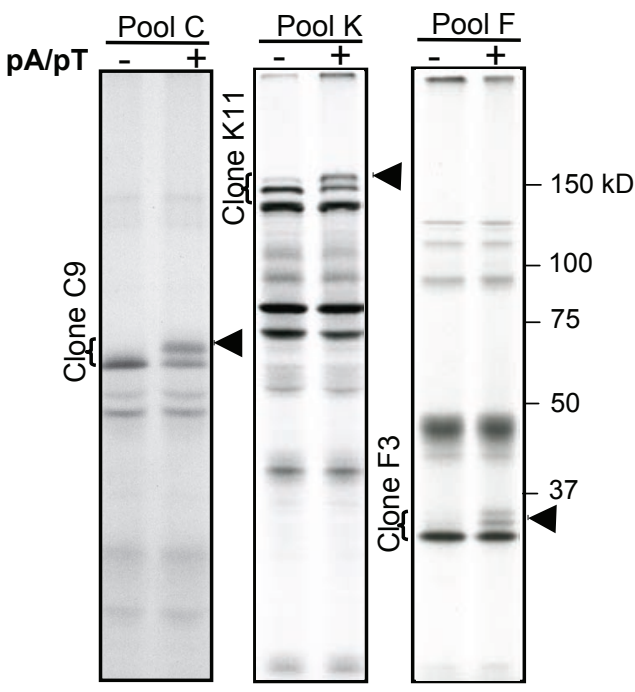

Buff

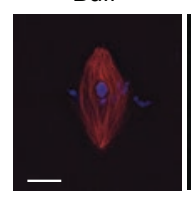

EcoRI

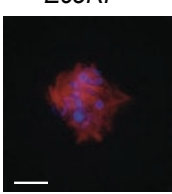

Buff

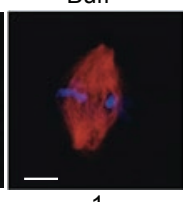

EcoRI

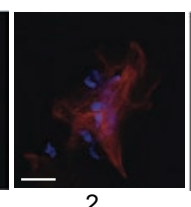

Buff
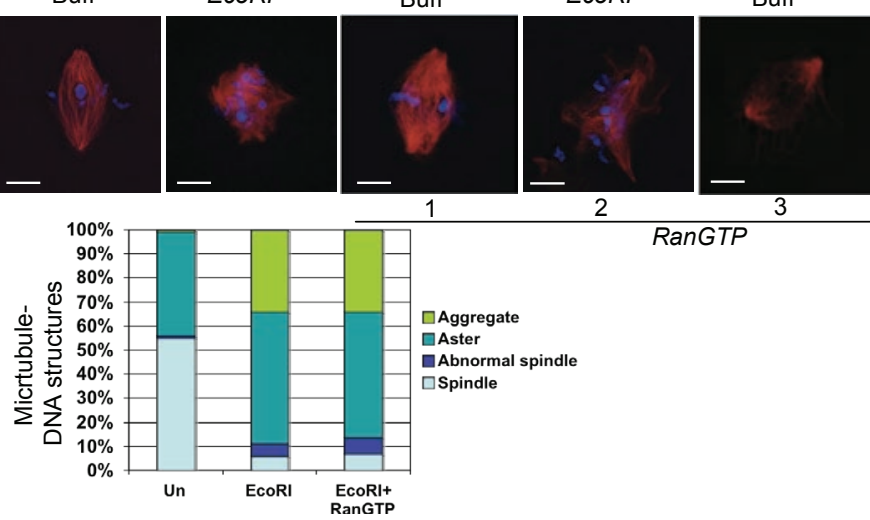

RanGTP

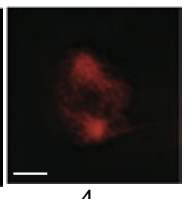

H. sapiens
G. gallus
X.

X. laevis

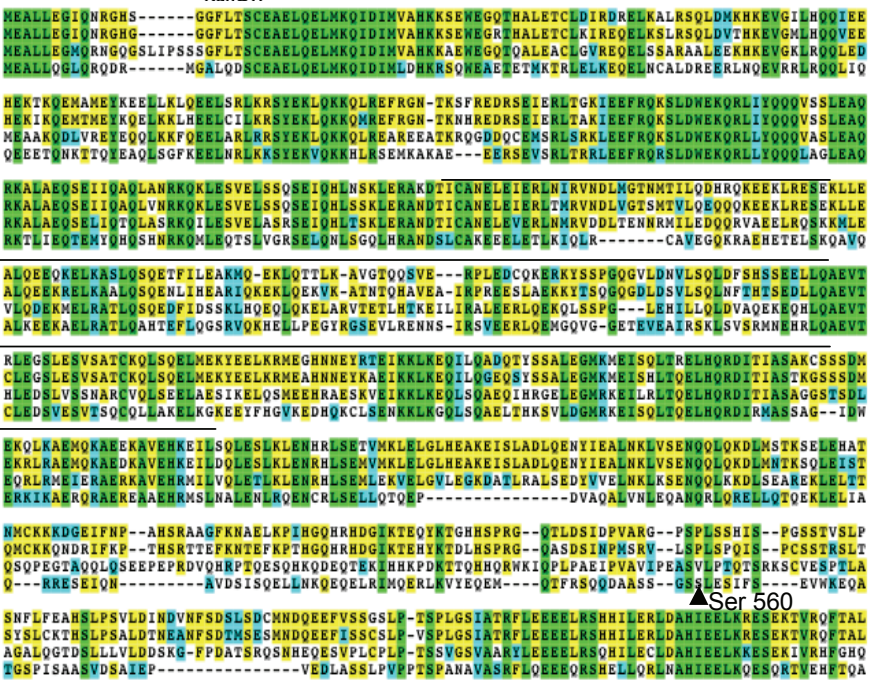

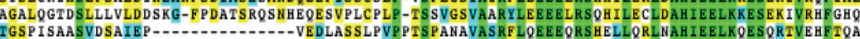
$\mathbf{V}$
$\mathbb{R}$
$\mathbb{R}$

Figure S2 Analysis of spindle assembly pathways affected by DNA damage and identification of ATM and ATR target. a, Analysis of $P / x 1$ role in spindle assembly in the presence of active ATM and ATR. Spindle assembly was obtained by incubation for 90 minutes of sperm nuclei in untreated CSF extracts (Un), in extracts supplemented with $0.25 \mathrm{U} / \mu \mathrm{I} E c O R I(E c o R /)$ or with $0.25 \mathrm{U} / \mu \mathrm{l} E c 0 R /$ and $80 \mathrm{ng} / \mu \mathrm{l}$ purified recombinant Xenopus PIX1 (PIx1). The graph shows the quantification of the different DNA associated microtubule structures found in untreated extracts (Un), extracts treated with $0.25 \mathrm{U} / \mu \mathrm{l} E c o R /$ and extracts treated with and $80 \mathrm{ng} / \mu \mathrm{l}$ purified recombinant Xenopus PIXI (EcoRI+PIX1). Scale bar, $10 \mu \mathrm{m}$. b, Analysis of the Ran-GTP pathway in spindle assembly in the presence of active ATM and $A T R$. Spindles were assembled in the presence of sperm nuclei and buffer (Buff) or $0.25 \mathrm{U} / \mu \mathrm{l} E c o R I$ (EcoRI). Some extracts were supplemented with $2.5 \mu \mathrm{M}$ recombinant RanQ68L (RanGTP). Fields showing DNA associated microtubule structures (panels 1 and 2) and DNA independent spindle structures (panels 3 and 4). The graph shows the quantification of the different DNA associated microtubule structures found in untreated extracts (Un), extracts treated with $0.25 \mathrm{U} / \mu \mathrm{l} E c o R I(E c o R I)$ or $0.25 \mathrm{U} / \mu \mathrm{l}$ $E c o R I+2.5 \mu \mathrm{M}$ recombinant RanQ68L (EcoRI + RanGTP). Scale bar, 10 $\mu \mathrm{m}$. c, cDNA expression screening to identify ATM and ATR targets. Pools of Xenopus cDNAs derived from a library of 7296 full length clones made from maternal mRNA. Clones individually arrayed in 384 well-plates were transcribed and translated in reticulocyte lysates in the presence of ${ }^{35}$-S labelled methionine. Lysates were mixed with egg extracts supplemented with (+) or without (-) linear DNA (pA/pT) and run on 10\% SDS-PAGE. An example of 3 pools $(C, K, F)$ of translated proteins is shown in the figure. Each pool contains a different shifting clone (C9, K11, F3). C9 is the original XCEP63 clone. On average we identified 1 to 3 shifting clones every 384 well plate. The position of the clones in the 384 well plates was derived by intersecting the pools corresponding to rows and columns of each plate. ATM and ATR dependency of the DSB induced shift was tested on isolated clones by using ATM and ATR inhibitors (see Fig. 3). This screening procedure differs from in vitro direct phosphorylation using recombinant kinases. Translated proteins can be engaged by the ATM and ATR dependent DNA damage response in a physiological context as they interact with their natural partners and protein complexes present in egg extract. Most of the translated clones do not shift suggesting that the assay is specific. The assay was conducted using interphase egg extract. However, both mitotic and interphase extracts were able to initiate phosphorylation of translated cDNAs without significant differences. This was also true for XCEP63 whose DNA damage induced phosphorylation was equivalent in interphase and mitotic extracts. d, XCEP63 protein sequence and homology with its orthologs. Alignment of XCEP63 and its putative orthologs in the indicated species. Amino acid sequence identity is highlighted in green, similarity in yellow and blue. The arrow indicates the position of serine 560. The line marks the SMC domain. Sequences for CEP63 orthologs are from NCBI databases. 
a

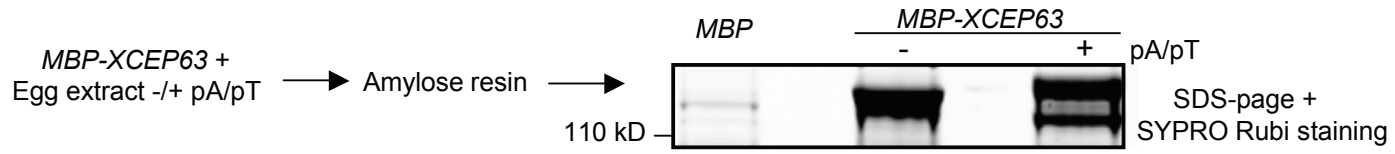

b

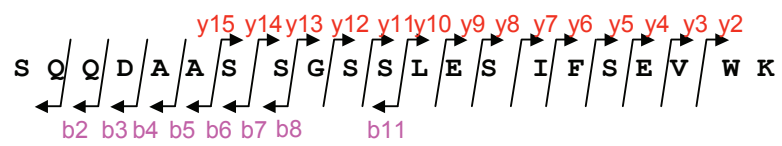

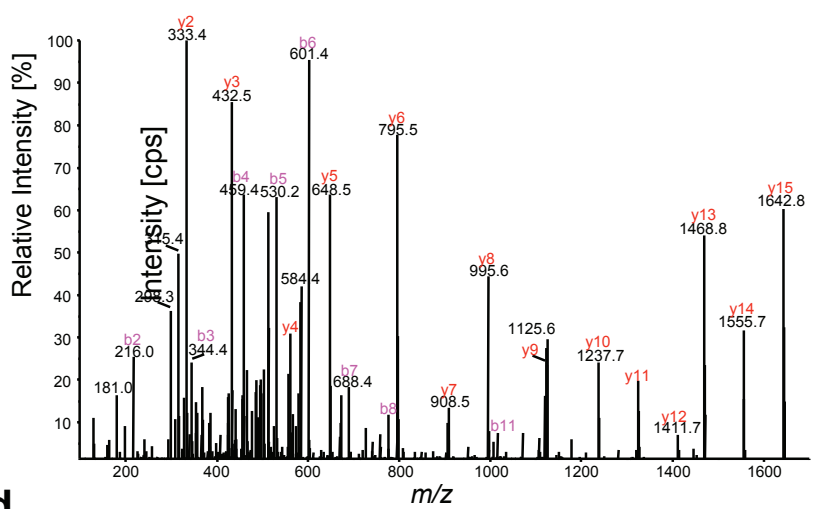

d

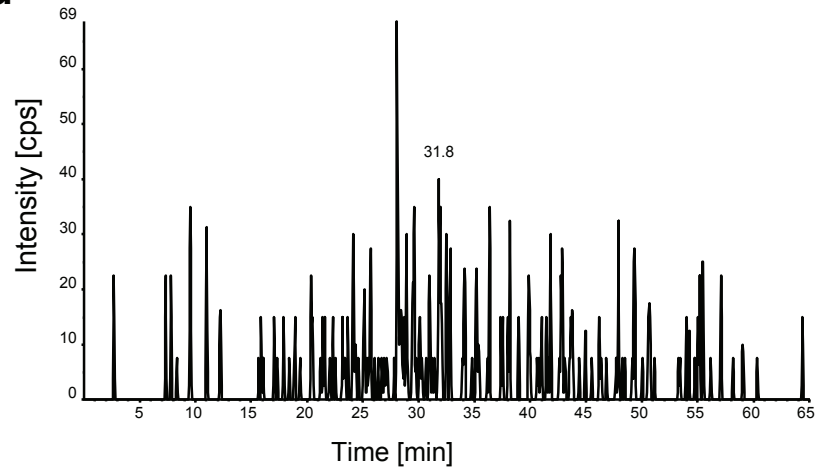

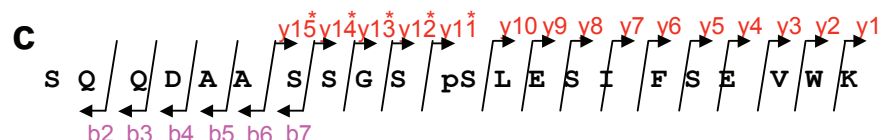
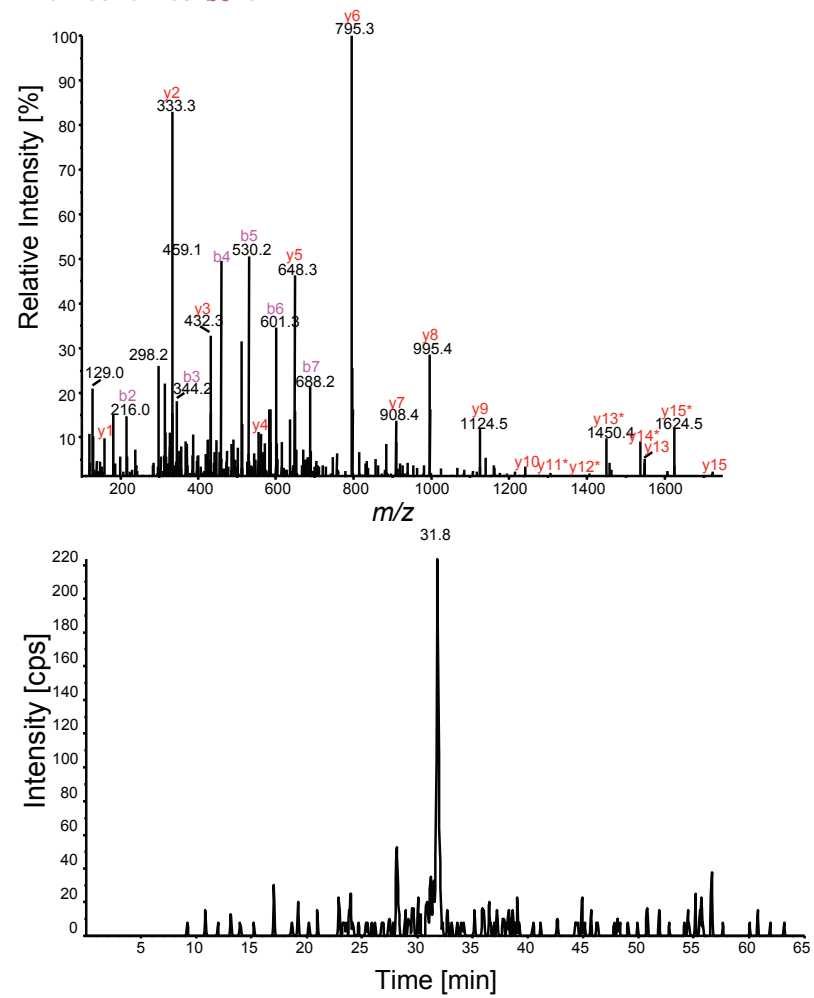

Figure S3 Identification of an ATM and ATR phosphoylation site on $X C E P 63$. a, Recombinant XCEP63 fused to $M B P$ was incubated in egg extract treated with or without $\mathrm{pA} / \mathrm{pT}$ for 1 hour at $23^{\circ} \mathrm{C} . M B P-X C E P 63$ was purified using amylose resin and run on SDS-PAGE, which was subsequently stained with SYPRO-Rubi stain. Gel slices containing $M B P-X C E P 63$ were subjected to mass spectrometry analysis. b, Mass spectrometry analysis of XCEP63 following ATM and ATR mediated phosphorylation in egg extract. Product Ion Spectrum of the doubly charged non-phosphorylated peptide SQQDAASSGSSLESIFSEVWK at $\mathrm{m} / \mathrm{z} 1122.0^{2+}$ observed in the sample containing MBP-XCEP63 isolated from egg extract treated with no $\mathrm{pA} / \mathrm{pT}$ at a retention time of $30.9 \mathrm{~min}$. c, Product lon Spectrum of the doubly charged phosphorylated peptide SQQDAASSGSPSLESIFSEVWK at $m / z 1162.12+$ observed in the sample containing XCEP63 isolated from egg extract treated with $\mathrm{pA} / \mathrm{T}$ at a retention time of 32.0 min. $y$ ions marked with an asterisk have undergone neutral loss of $98 \mathrm{Da}$, indicating the loss of phosphoric acid. $Y$ ions down to y11 exhibit this neutral loss, indicating that S560 is indeed the site of phosphorylation. d, Multiple Reaction Monitoring (MRM) traces observed in XCEP63 - pA/pT (left) and XCEP63 + pA/pT (right) for the transition $m / z 1162.1>795.4$ specific for the phosphopeptide sequence SQQDAASSGSPSLESIFSEVWK. Integration of the traces revealed a phosphopeptide ratio of 0.17 between samples - and $+p A / p T$. 


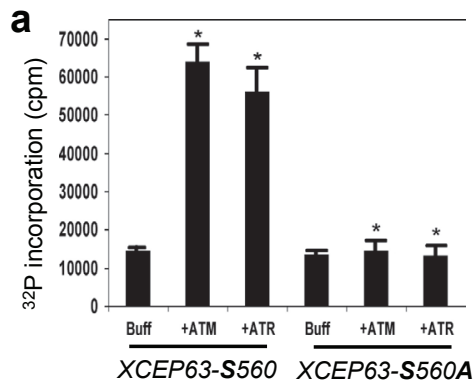

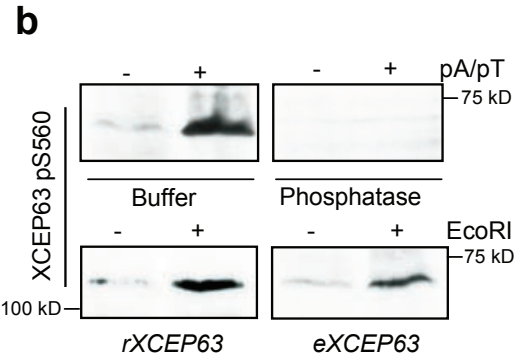
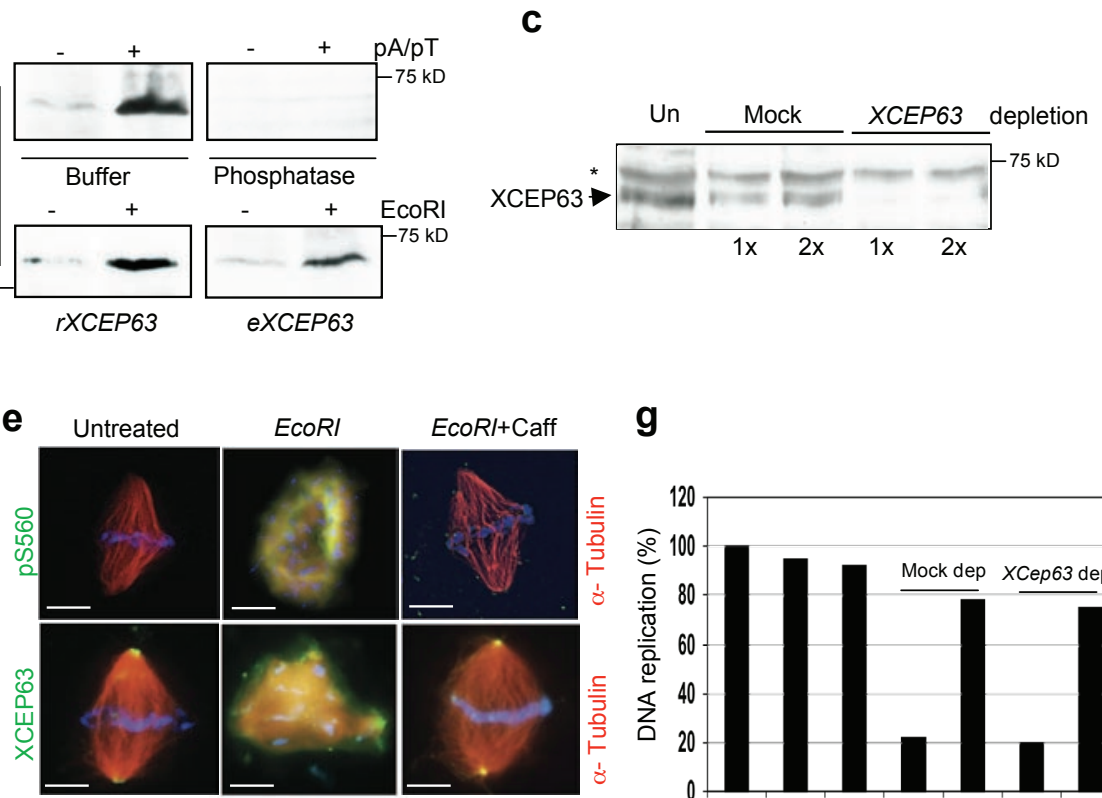

g
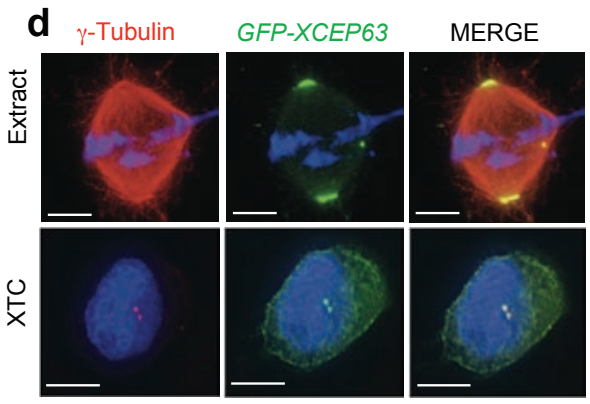

CPT

CPT+Caff
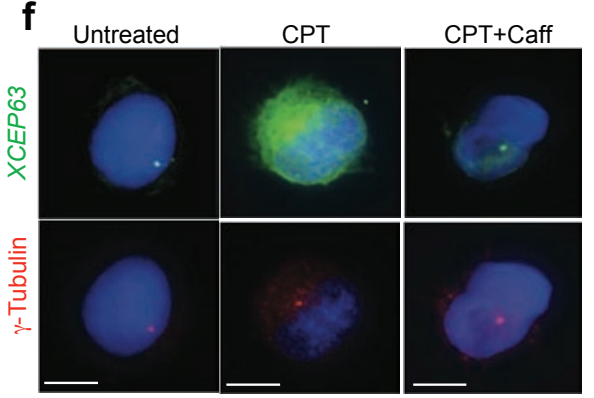

CPT + Caff

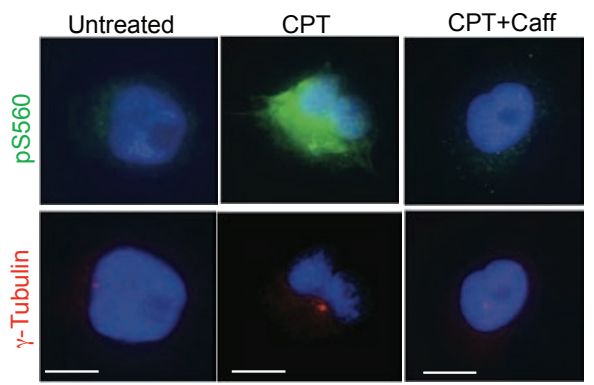

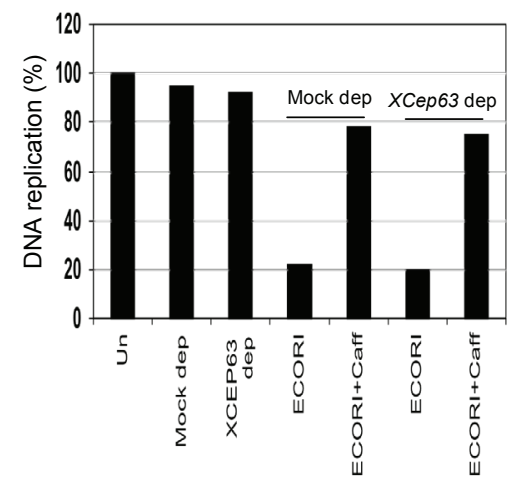

Figure S4 Analysis of XCEP63 function protein following ATMIATR dependent phosphorylation of serine 560. a, In vitro phosphorylation of XCEP63. XCEP63 peptides containing serine 560 (XCEP63-S560) or serine 560 mutated to alanine (XCEP63-S560A) were incubated with buffer, recombinant Flag-ATM (+ATM) or recombinant Flag ATR $(+A T R)$ in the presence of $\gamma^{32}$ P-ATP. The amount of radioactivity incorporated was reported in the graph (see Methods). The average values from three independent experiments are shown. Error bars stand for s.d. ${ }^{*} P<0.001$ compared with control with buffer. b, (Upper panels) Western blot of XCEP63 using anti phospho S560 antibodies performed on egg extract treated with (+) or without (-) $5 \mathrm{ng} / \mu \mathrm{l} \mathrm{pA/pT}$ in the presence of lambda phosphatase buffer (Buffer) or lambda phosphatase (Phosphatase). (Lower panels) Western blot using anti phospho-S560-XCEP63 antibodies performed on egg extract

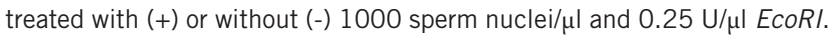
Extracts were supplemented with recombinant XCEP63 protein (rXCEP63) or left un-supplemented (eXCEP63). c, Western blot with anti XCEP63 antibodies of egg extract after mock depletion (Mock) or depletion with anti XCEP63 antibodies (XCEP63) performed once (1x) or twice (2x). * non-specific band. d, Localization of XCEP63 fused to GFP (GFP-XCEP63) added to extracts as reticulocyte translated protein (Extract) or transfected into Xenopus laevis XTC cells (XTC) (see Methods). Immuno-fluorescence was performed with specific anti $\gamma$-tubulin ( $\gamma$-tubulin) and anti GFP (GFP) antibodies. Scale bar, $10 \mu \mathrm{m}$. e, Immuno-fluorescence with anti $\alpha$-tubulin, anti phospho-serine 560 of XCEP63 (p560, upper panels) or anti XCEP63 antibodies (XCEP63 lower panels) of spindles assembled in untreated extracts (Untreated) and in extracts treated with EcoRI (EcoRI) or EcoRI and caffeine (ECORI + Caff). No phospho-serine 560 of CEP63 is detected in the absence of active ATM and ATR. Scale bar, $10 \mu \mathrm{m}$. f, Immuno-fluorescence with anti XCEP63 (XCEP63, upper left panels), anti $\gamma$-tubulin (lower panels) and anti-phospho-serine-560 of XCEP63 (p560, upper right panels) of XTC cells that were untreated (Untreated), incubated with $400 \mathrm{nM}$ CPT (CPT) or $400 \mathrm{nM}$ CPT and $5 \mathrm{mM}$ caffeine (CTP + Caff). Scale bar, $10 \mu \mathrm{m}$. g, DNA replication monitored in untreated (Un), mock depleted (Mock dep), XCEP63 depleted (XCEP63 dep) interphase egg extracts in the presence and in the absence of $0.1 \mathrm{U} / \mu \mathrm{l} E \mathrm{CORI}(E \mathrm{COR} /)$ or $0.1 \mathrm{U} / \mu \mathrm{l} E \mathrm{COR} /$ and $3 \mathrm{mM}$ caffeine $(E C O R I+$ Caff $)$ as indicated. 
a

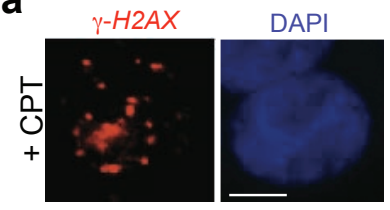

d

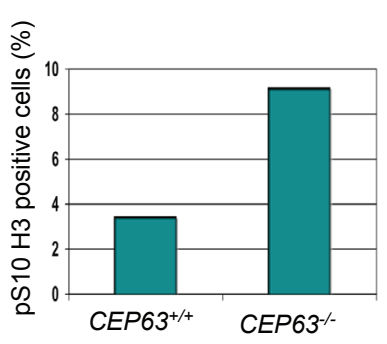

g

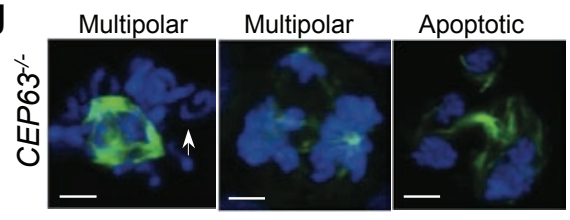

h

$75 \mathrm{kD}$

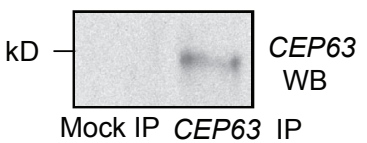

b
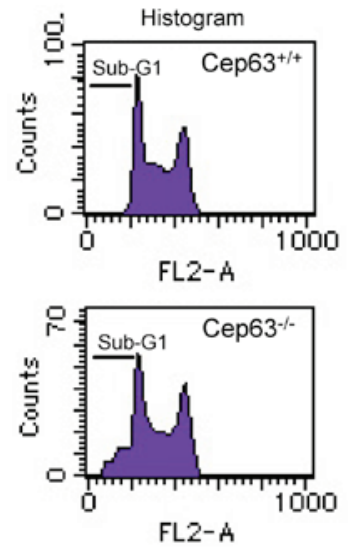

FL2-A

e

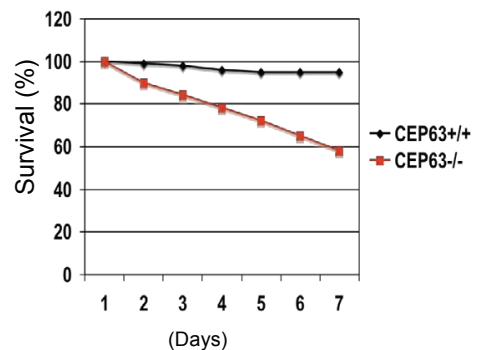

FL2-A
C
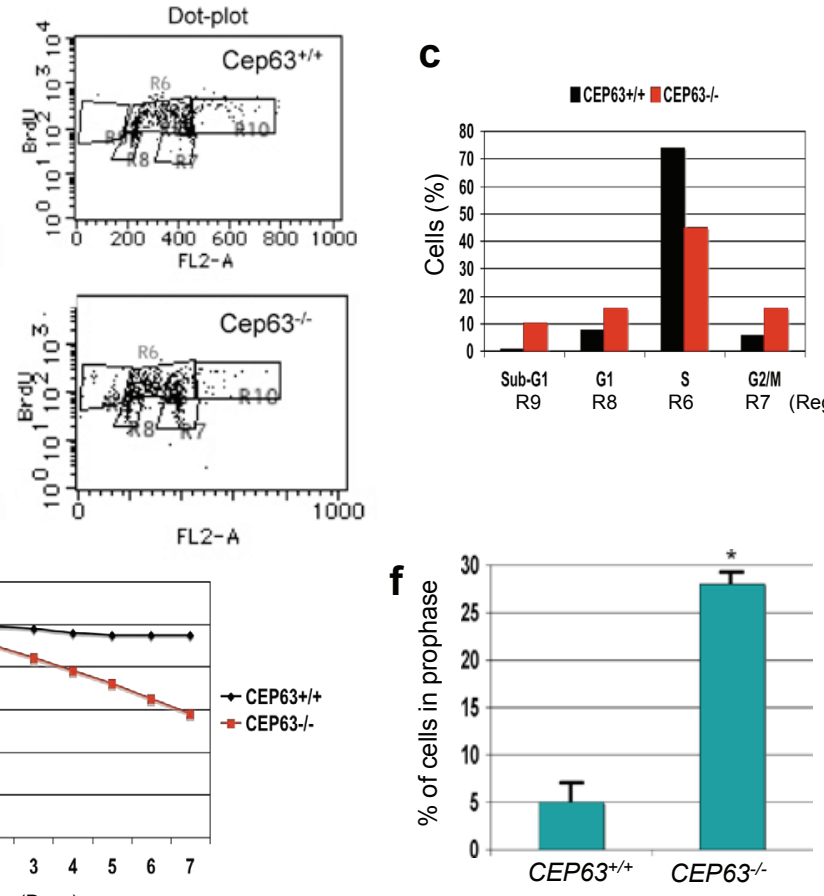

ПCEP63+/+ \CEP63\%

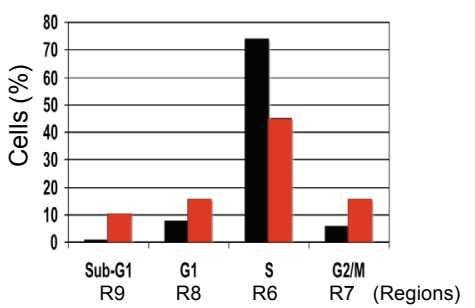

i

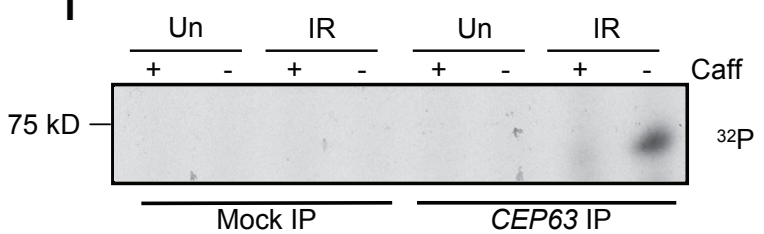

Figure S5 Analysis of CEP63's function in DT40 cells. a, Immuno-

fluorescence of DT40 cells showing chromosomal breakage induced histone H2AX phosphorylation following treatment with $1 \mu \mathrm{M}$ CPT. Scale bar, 5 $\mu \mathrm{m}$. b. Histograms and dot plots showing FACS profiles of asynchronous CEP63 $3^{+/+}$and $C E P 63^{-/-}$cells. c, Bar graph reporting the quantification of the different cell cycle phases of $C E P 63^{+/+}$and $C E P 63^{-/-}$cells after $\mathrm{BrdU}$ incorporation. The bars reflect the number of cells quantified in the corresponding areas (Regions) of the FACS dot plot d, Mitotic index obtained by counting phospho-histone $\mathrm{H3}$-positive $\mathrm{CEP} 63^{+/+}$and $C E P 63^{-/-}$cells. e, Survival curve showing percentage of vital $C E P 63^{+/+}$and $C E P 63^{-/-}$cells collected at the indicated times after seeding. Cells were stained with Trypan blue to monitor vitality. f, Percentage of $C E P 63^{+/+}$and $C E P 63^{-/-}$cells arrested in prophase 60 minutes after nocodazole release. The average values from three independent experiments are shown. Error bars stand for s.d. ${ }^{*} P<0.001$ compared with untreated control. g, Additional examples of $C E P 63^{-/-}$cells with multipolar spindles. Arrow indicates chromosome detached from spindle. Cells with condensed apoptotic nuclei are also shown. Cells were stained with anti $\alpha$-tubulin antibodies. Scale bar, 5 $\mu \mathrm{m}$. h, Anti CEP63 western blot of DT40 cell lysates immunoprecipitated with protein A sepharose beads (Mock IP) or protein A sepharose beads coupled to affinity purified anti avian CEP63 antibodies (CEP63 IP). i, Autoradiography of lysates of DT40 cells labelled with ${ }^{32} \mathrm{P}$ (see Methods) immunoprecipitated with protein A sepharose beads (Mock IP) or protein A sepharose beads coupled to affinity purified anti avian CEP63 antibodies (CEP63 IP). Cells were untreated (Un) or irradiated with 10 Gys (IR) in the absence or in the presence of $5 \mathrm{mM}$ caffeine (Caff). 


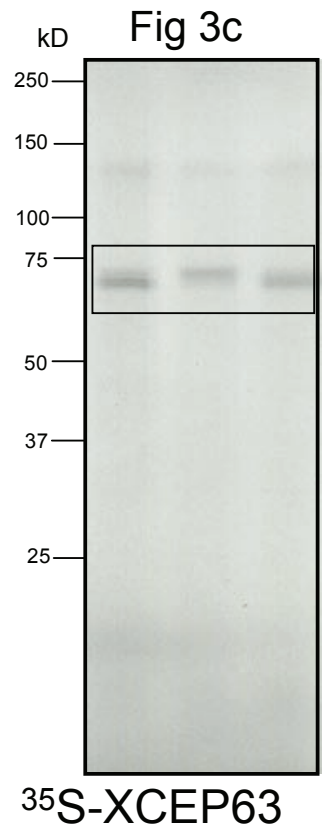

Fig 3d

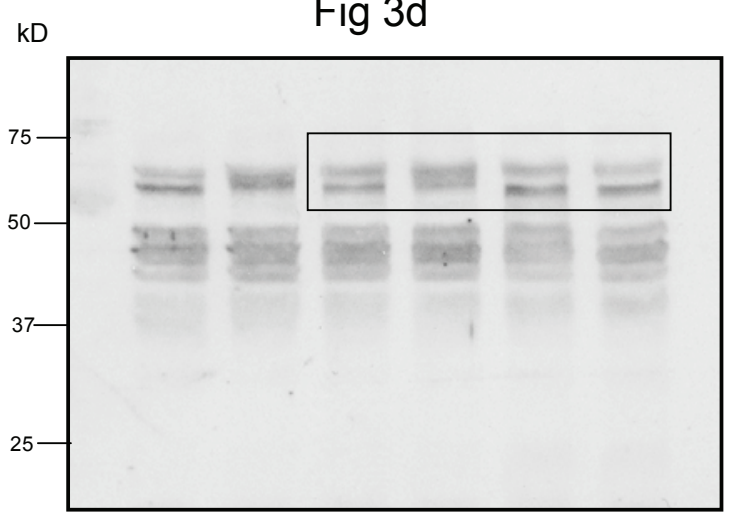

IB: XCEP63

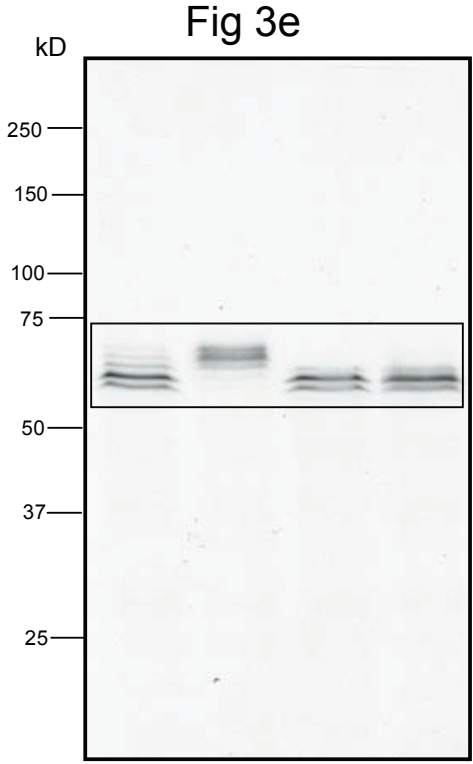

${ }^{35} \mathrm{~S}-\mathrm{XCEP} 63$

Figure S6 Full scans of key gel/western data. Rectangles delimit cropped areas used in the indicated figures. 
Fig $3 f$
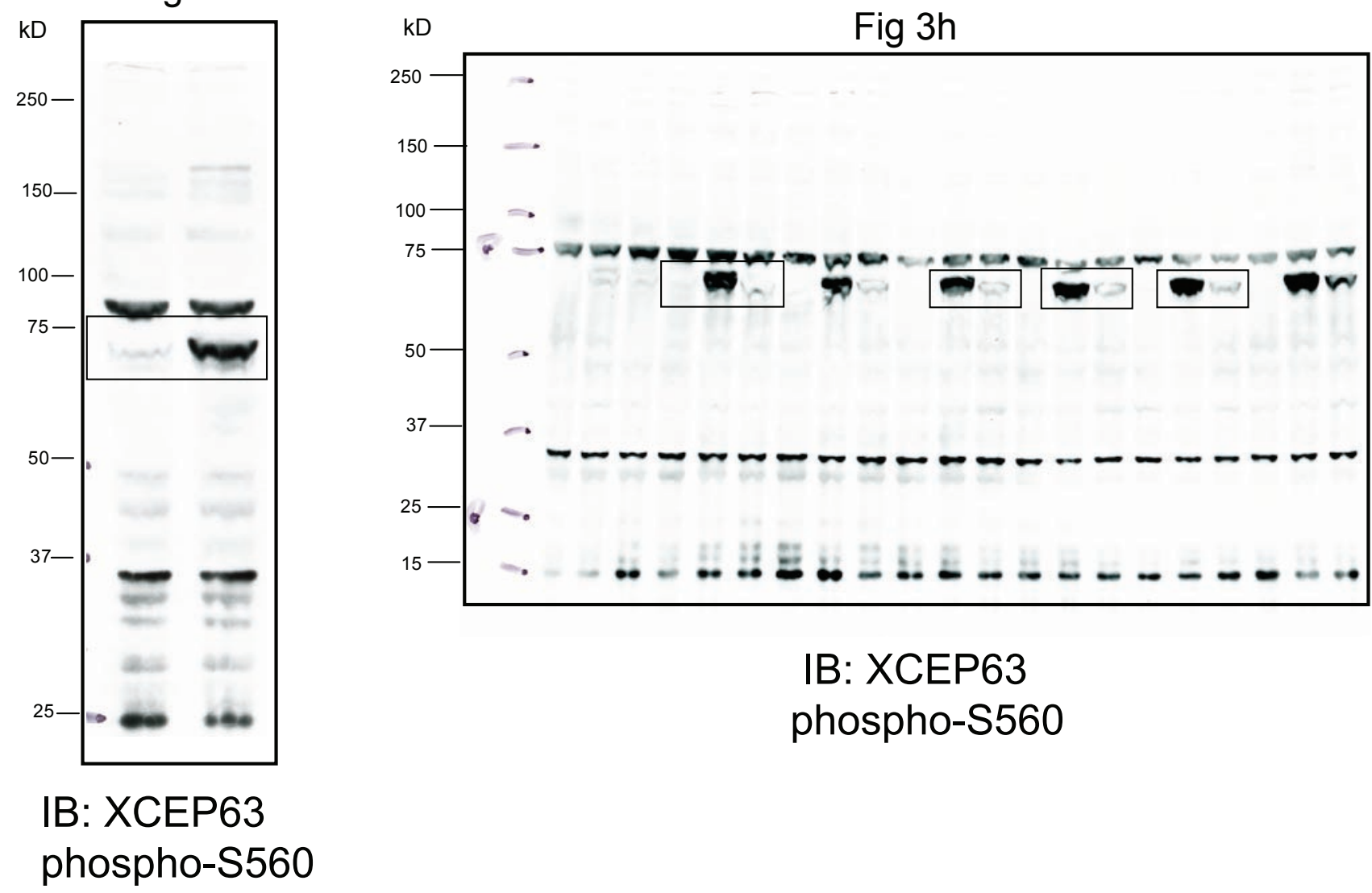

Figure S6 continued 
Fig $5 e$

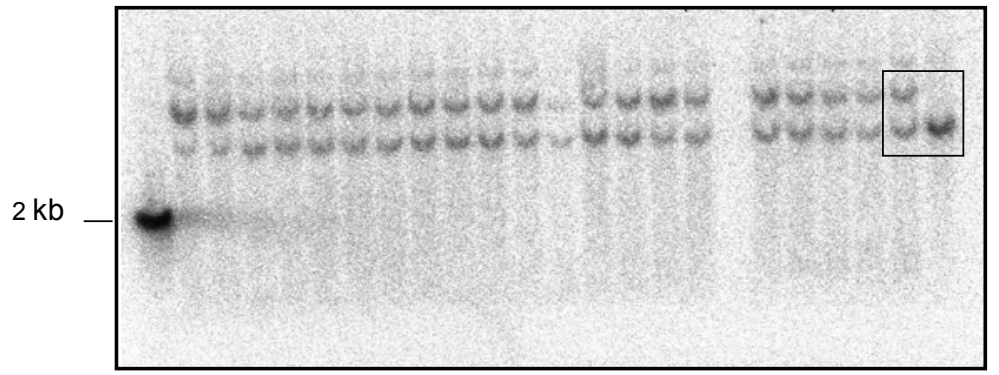

SB: CEP63

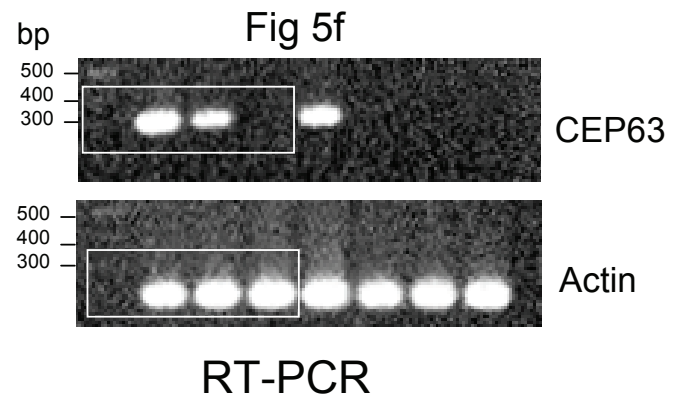

Fig $5 g$

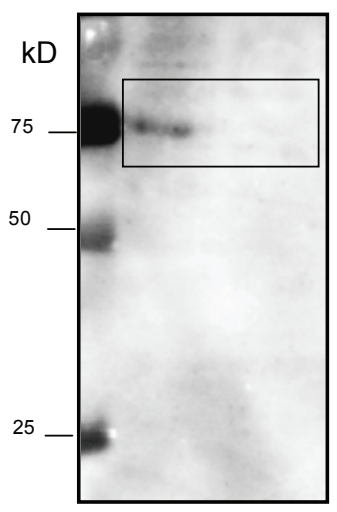

IB: CEP63

Figure S6 continued 


\section{SUPPLEMENTARY METHODS}

\section{DNA-coated beads}

Chromatin beads were prepared using byotinilated DNA and Dynal Kilobinder kit (Invitrogen) essentially as decribed ${ }^{3}$ with few modifications and used in egg extract ${ }^{2}$. Briefly, a $5.4 \mathrm{~kb}$ plasmid (PCDNA3), was prepared with Qiagen miniprep kit. DNA was cut using EcoRI and NotI so that one end of the fragment terminates in an overhang containing $\mathrm{G}$ and $\mathrm{C}($ Not $I)$ and the other only A and $\mathrm{T}$ (EcoRI). DNA was ethanol precipitated, resuspended in TE buffer and subjected to fill in reaction. Fill reaction were performed in $80 \mu \mathrm{l}$ volume in the presence of $35 \mu \mathrm{g}$ DNA, 1x Klenow buffer, $20 \mathrm{U}$ Klenow (Roche), $50 \mu \mathrm{M}$ biotin-dATP, $50 \mu \mathrm{M}$ biotin dUTP (Invitrogen), $50 \mu \mathrm{M}$ thio$\mathrm{dCTP}$ and $50 \mu \mathrm{M}$ thio-dGTP (tebu). Reactions were incubated for 2 hours at $37^{\circ} \mathrm{C}$. Unincorporated nucleotides were removed using G-25 spin columns (Pharmacia).

Biotinilated DNA was coupled to streptavidin Dynal beads using Kilobase Binder kit (Invitrogen). $4 \mu \mathrm{l}$ beads were used for each $\mu \mathrm{g}$ of DNA to couple in $1 \mathrm{ml}$ final volume of Binding buffer according to manufacturer instructions. Coupling reaction were carried out at $16^{\circ} \mathrm{C}$ overnight on a rotator. The amount of DNA immobilized was measured comparing DNA concentration of samples taken before and after coupling. The beads were washed with washing solution (Invitrogen) and in bead buffer $(1.5 \mathrm{M} \mathrm{NaCl}, 10 \mathrm{mM}$ Tris, $1 \mathrm{mM}$ EDTA, $\mathrm{pH}$ 7.6). After the last wash beads were re-suspended in bead buffer at a final concentration of $1 \mu \mathrm{g}$ DNA/10 $\mu \mathrm{l}$ beads. DNA coated beads were used DNA concentration of $5 \mathrm{ng} / \mu \mathrm{l}$ to induce anastral spindle assembly as described above. Linear plasmid PCDNA3 cut with EcoRI was used as control in Figure 2c.

\section{Western Blotting}

Samples from extracts treated as indicated in figure legend were diluted in loading buffer, boiled for 3 minutes, electrophoresed on SDS-PAGE, transferred to nitrocellulose membranes, and probed with polyclonal antibodies specific for Xenopus XCEP63, anti phospho serine 560, anti ATM pS1981 (Rockland) and anti human Chk1 (Abcam) or anti chicken CEP63. Phosphatase treatment of endogenous XCEP63 was performed incubating samples with lambda phosphatase (NEB) for 30 minutes at $30^{\circ} \mathrm{C}$ according to manufacturer instructions.

\section{$H 2 A X$ kinase assay}

Histone $H 2 A X$ kinase activity was performed as described with modifications ${ }^{1}$. Briefly CSF egg extracts were incubated with linear DNA at $5 \mathrm{ng} / \mu \mathrm{l}$, linear DNA and $20 \mu \mathrm{M} \mathrm{Ku}-55933$, linear DNA and $2 \mathrm{mM}$ caffeine or sperm heads and $0.25 \mathrm{U} / \mu \mathrm{L}$ EcoRI for 30 minutes at $20^{\circ} \mathrm{C}$. Extract $(2 \mu \mathrm{l})$ was mixed with $20 \mu \mathrm{l}$ of EB kinase buffer $(20 \mathrm{mM}$ HEPES [pH 7.5], $50 \mathrm{mM} \mathrm{NaCl}, 10 \mathrm{mM} \mathrm{MgCl}$, $1 \mathrm{mM}$ DTT, $1 \mathrm{mM} \mathrm{NaF}, 1 \mathrm{mM} \mathrm{Na} \mathrm{VO}_{4}$, and $10 \mathrm{mM} \mathrm{MnCl} \mathrm{M}_{2}$ ) supplemented with $0.5 \mathrm{mg} / \mathrm{ml}$ histone $H 2 A X$ peptide (Sigma-Genosys), $50 \mu \mathrm{M}$ ATP and 1 $\mu 1$ of $\gamma-{ }^{32} \mathrm{P}$-ATP $10 \mathrm{mCi} / \mu \mathrm{l}$ (greater than $3,000 \mathrm{Ci} / \mathrm{mmol}$ ). Samples were incubated at $30^{\circ} \mathrm{C}$ for 20 minutes, and reactions were spotted on p81 phosphocellulose filter paper (Upstate Biotechnology, Lake Placid, New York, United States). Filters were air-dried and washed three times in 5\% phosphoric acid. Radioactivity was quantified in a scintillation counter. The extract used to measure $H 2 A X$ phosphorylation was pre-incubated twice for 20 min 
at $4^{\circ} \mathrm{C}$ with a volume of streptavidin-coated beads (Dynal) coupled to $5^{\prime}$ biotinylated linear DNA to eliminate DNA-PK activity towards histone $H 2 A X$.

-ATM and ATR activity induced by chromatin beads:

Histone $H 2 A X$ kinase activity in the presence of chromatin beads was performed in a similar fashion. CSF extracts were supplemented with Dynal (Invitrogen) streptavidin beads, byotinilated DNA bound to streptavidin beads or PCDNA3 plasmid linearized with EcoRI $(\mathrm{DSB})$ at $5 \mathrm{ng} / \mu \mathrm{l}$. Extracts were released in interphase with $0.4 \mathrm{mM} \mathrm{CaCl} \mathrm{C}_{2}$ and incubated for 2 hour at $20^{\circ} \mathrm{C}$. Fresh CSF extract was added and incubated for 45 minutes. $2 \mu \mathrm{l}$ samples were taken and processed as described above to measure histone $H 2 A X$ phosphorylation.

\section{Cdk1 and $P l x 1$ activity}

CSF extracts were supplemented with 1000 sperm nuclei/ $\mu 1$ and treated as indicated in Fig. $2 \mathrm{a}$ and 2 b. $2 \mu \mathrm{l}$ samples were taken at the indicated times and incubated with EB buffer supplemented with $0.5 \mathrm{mg} / \mathrm{ml}$ histone $\mathrm{H} 1,50 \mu \mathrm{M}$ ATP and $1 \mu 1$ of $\gamma-{ }^{32} \mathrm{P}$-ATP, 10 $\mathrm{mCi} / \mathrm{ml}(>3000 \mathrm{mC} / \mu \mathrm{l})$. Samples were incubated at $30^{\circ} \mathrm{C}$ for $20 \mathrm{~min}$ and reactions were spotted on p81 phosphocellulose squares (Upstate). Unincorporated $\gamma-{ }^{32} \mathrm{P}$-ATP was washed with $5 \%$ ortophosphoric acid and radioactivity was read in a scintillation counter. For Plx 1 activity $20 \mu \mathrm{l}$ extract were taken at the time indicated in Fig. $2 \mathrm{~b}$ and incubated with $5 \mu \mathrm{l}$ of anti Plxl serum in $200 \mu \mathrm{l}$ of PBS. After 1-hour incubation on a roller Protein A sepharose beads were added and incubated for 1 additional hour. Plxl immunoprecipitates were then washed in PBS containing $0.2 \%$ NP40 and then incubated with EB buffer supplemented with $0.5 \mathrm{mg} / \mathrm{ml}$ Casein (Sigma), $50 \mu \mathrm{M}$ ATP and $1 \mu \mathrm{l}$ of $\gamma$ -

${ }^{32} \mathrm{P}$-ATP, $10 \mathrm{mCi} / \mathrm{ml}(>3000 \mathrm{mC} / \mu \mathrm{l})$. Samples were incubated at $30^{\circ} \mathrm{C}$ for 20 minutes and reactions were separated on SDS-page which was stained with Coumassie, dried and exposed. Bands corresponding to casein were excised and counted in scintillation counter. Anti Xenopus Plxl antibodies were previously described ${ }^{5}$

\section{Recombinant proteins, antibodies and depletions}

Full-length wild type XCEP63 cDNA inserted into pCS2 plasmid was isolated from a cDNA library used for $A T M$ and $A T R$ substrate screening performed as described ${ }^{4}$. Wild type and serine 560 to alanine mutant of Xenopus XCEP63 cDNA were cloned into in pDEST 17 (Invitrogen) or custom made pDEST-MAL (a gift from Simon Boulton) to produce 6xHis and Maltose binding protein fused (MBP) fused XCEP63.

Full length 6xHis-XCEP63 was expressed using BL21-AI (Invitrogen) cells induced with arabinose. 6xHis-XCEP63 protein was purified in denaturing conditions according to Qiagen protocol on Nichel resin (Qiagen). Polyclonal antibodies were obtained by injecting 4 rabbits with purified 6xHis-XCEP63 protein (Harlan serum).

Polyclonal antibodies against chicken $C E P 63$ were obtained by injecting 4 rabbits with 2 peptides (SLIPSSSGSL) and (QEDFIDSSKLHQE) derived from chicken CEP63 protein sequence present on NCBI, produced by the LRI peptide facility and conjugated to KLH (Pierce) according to manufacturer instruction. 
Maltose binding protein fused proteins $M B P-X C E P 63$ and MBP-XCEP63-S638A were expressed using BL21 (Invitrogen) and purified in native conditions on amylose resin (NEB) according to manufacturer's protocol for isolation of $M B P$ fusion proteins.

XCEP63 serine to alanine (XCEP63-S560A) mutant cDNAs was obtained using QuickChange (Stratagene) according to manufacturer instructions.

Plasmids to express histidine-tagged-human Xenopus Plxl were previously described ${ }^{5}$

For XCEP63 depletion $50 \mu \mathrm{l}$ extracts were depleted using $25 \mu \mathrm{l}$ Protein A sepharose beads (Amersham) coupled to $100 \mu \mathrm{l}$ of anti XCEP63 serum. Beads were extensively washed with CSF-XB buffer $\left(100 \mathrm{mM} \mathrm{KCl}, 0.1 \mathrm{mM} \mathrm{CaCl}_{2}, 10 \mathrm{mM}\right.$ HEPES, $\mathrm{pH}$ 7.7, 50 $\mathrm{mM}$ Sucrose, $5 \mathrm{mM}$ EGTA, $2 \mathrm{mM} \mathrm{MgCl}$ ) before mixing with extracts. Mock depletion was performed using Protein A sepharose.

\section{Immuno-fluorescence}

Cells and spindles were cultured or spun on poly-L-lysine-coated as described. The coversips were fixed for 2 minutes in $-20^{\circ} \mathrm{C}$ methanol, rehydrated in Tris-buffered saline (TBS), blocked with blocking buffer (TBS, $0.1 \%$ Triton X-100, and $2 \%$ bovine serum albumin [BSA]), and stained for $1 \mathrm{~h}$ with primary antibodies (anti $\gamma-$ or $\alpha$-Tubulin (Sigma), anti phospho histone $H 2 A X$ (Cell signaling), anti GFP and anti XCEP63 antibodies or anti phospho-Serine 560 of XCEP63 antibodies) diluted in blocking buffer. Secondary commercial antibodies against anti mouse and rabbit IgGs conjugated to Rhodamine, Fluorescein, $\mathrm{Cy} 3$ or Cy5 (Invitrogen) were used. After staining DNA with 2 $\mu \mathrm{g} / \mathrm{ml}$ Hoechst 33342 or DAPI, coverslips were mounted in $90 \%$ glycerol, $1 \mathrm{mg} / \mathrm{ml} p$ phenylenediamine, $20 \mathrm{mM}$ Tris-Cl, $\mathrm{pH} 8.8$. Immuno-fluorescence on spindle assembled in extracts and spun on poly-L-lysine-coated coverslips was performed in a similar way. All images were acquired at room temperature using a Deltavision microscope.

\section{In vitro $X T C$ cell culture and transfection}

Xenopus tissue culture (XTC) cells were cultured in 70\% Leibovitz L-15 medium plus $10 \%$ fetal bovine serum, $100 \mathrm{U} / \mathrm{ml}$ penicillin, and $100 \mu \mathrm{g} / \mathrm{ml}$ streptomycin.

XTC cells were cultured on poly-L-lysine-coated coverslips. Cells were collected and processed for immuno-staining as already described.

Mitotic XTC cells were obtained by a double-thymidine block: 12 hours of $2 \mathrm{mM}$ thymidine (Sigma) were added to medium to obtain the first block followed by a 9 hour release in normal medium with no thymidine. $2 \mathrm{mM}$ thymidine were added for additional $12 \mathrm{~h}$ (second block) and then released into medium with $25 \mu \mathrm{M}$ MG-132. 8 hours after the release as cells entered mitosis a batch of cells was irradiated at 10 Gys in the presence or in the absence of $5 \mathrm{mM}$ caffeine. Irradiation was performed with a source of ${ }^{137}$ Cs.

Cells were collected and processed for immuno-staining as already described with anti $\alpha$ tubulin and anti histone H3-phospho-Serine 10 (Abcam). Spindle morphology was monitored in cells with condensed chromosomes positive for anti histone H3-phosphoSerine 10. 
Transfection with plasmid encoding GFP-XCEP63 was performed on asynchronous cells. GFP-XCEP63 plasmid was constructed using Invitrogen Gateway vector pDEST-47 using FuGene (Roche) according to manufacturer instructions.

\section{Identification of $A T M$ and $A T R$ phosphorylated residue on XCEP63}

$A T M$ Phosphorylation site on XCEP63 was determined using the following strategy. Briefly, $20 \mu \mathrm{l}$ of $1 \mathrm{mg} / \mathrm{ml} M B P$ or $M B P-X C E P 63$ protein was incubated with egg extract in the absence or in the presence of $5 \mathrm{ng} / \mu 1 \mathrm{pA} / \mathrm{pT}$ at $23^{\circ} \mathrm{C}$ for 60 minutes. $M B P$ and $M B P-X C E P 63$ proteins were isolated from egg extract diluted 1:2 with EB buffer using amylose resin according to the manufacturer protocol (NEB). Proteins were eluted with laemmli buffer and run on SDS-PAGE. Gel was stained with SYPRO-Rubi (Invitrogen). Gel slices corresponding to $M B P-X C E P 63$ were isolated and processed for Mass spectrometry analysis.

Excised gel bands were cut into approximately $1 \mathrm{~mm}$ cubes, and subsequently washed with water and $50 \% \mathrm{CH}_{3} \mathrm{CN} / 20 \mathrm{mM} \mathrm{NH}_{4} \mathrm{HCO}_{3}$. After dehydration of the gel pieces with $\mathrm{CH}_{3} \mathrm{CN}$, they were reduced $\left(10 \mathrm{mM}\right.$ DTT in $100 \mathrm{mM} \mathrm{NH} \mathrm{HCO}_{3}, 1 \mathrm{~h}$ at $\left.56^{\circ} \mathrm{C}\right)$ and alkylated ( $55 \mathrm{mM}$ iodoacetamide in $100 \mathrm{mM} \mathrm{NH}_{4} \mathrm{HCO}_{3}, 45 \mathrm{~min}$ at $\mathrm{RT}$ in the dark). The gel pieces were washed with $50 \% \mathrm{CH}_{3} \mathrm{CN} / 20 \mathrm{mM} \mathrm{NH} \mathrm{HCO}_{3}$ and dehydrated with $\mathrm{CH}_{3} \mathrm{CN}$. Then, sequencing grade porcine trypsin (Promega) was added $(10 \mu \mathrm{g} / \mu \mathrm{l}$ in 20 $\mathrm{mM} \mathrm{NH} \mathrm{HCO}_{3}$ ) and the samples were left on ice for $45 \mathrm{~min}$. After that, the excess buffer and trypsin was discarded, the gel pieces were covered with $20 \mathrm{mM} \mathrm{NH}_{4} \mathrm{HCO}_{3}$ alone and left at $37{ }^{\circ} \mathrm{C}$ overnight. Finally, the supernatant was collected and additional peptides were extracted from the gel pieces with $50 \% \mathrm{CH}_{3} \mathrm{CN} / 0.1 \% \mathrm{TFA}$. These washes were added to the previously collected supernatant and dried in a Speedvac.

\section{Mass spectrometry analysis}

Tryptic peptides were separated by reversed phase-C18 chromatography on a Tempo 1D nanoLC system (Applied Biosystems, Foster City, CA, USA). The eluent was analysed on a 4000 Q TRAP hybrid triple quadrupole/linear ion trap mass spectrometer equipped with a nanoDCI source (Applied Biosystems) in an information-dependent acquisition mode. An electrospray voltage of $2800 /-2800 \mathrm{~V}$, an interface heater temperature of $150^{\circ} \mathrm{C}$, and a cone voltage of $60 /-85 \mathrm{~V}$ were used for positive and negative ion mode analysis, respectively. The collision energy was dynamically adjusted according to the charge state and $\mathrm{Mr}$ of the precursors.

Three different types of LC/MS/MS analyses were performed to obtain both qualitative and quantitative information about XCEP63 phosphorylation:

a) a regular LC/MS/MS analysis consisting of a linear ion trap MS full scan, a high resolution linear ion trap experiment of the five most abundant MS precursors to determine charge state and molecular weight, and up to five linear ion trap product ion spectra per cycle, all in positive ion mode. The goal of this experiment was to establish protein identity at high sequence coverage.

b) an LC/MS/MS analysis consisting of a Precursor Ion Scan for $\mathrm{m} / \mathrm{z} 79$ in negative ion mode, a high resolution linear ion trap experiment of the two most abundant 
precursors in negative ion mode and, following a polarity switch, up to two linear ion trap product ion spectra in positive ion mode per cycle. The goal of this experiment was to selectively identify phosphorylated peptides ${ }^{8}$.

c) A semiquantitative LC/MS/MS experiment consisting of Multiple Reaction Monitoring (MRM) for both observed and predicted ion fragmentation reactions in positive ion mode, followed by up to two linear ion trap product ion spectra in positive ion mode per cycle. The goal of this experiment was to confirm or reject the identity of the phosphopeptide candidates observed in b), and to obtain relative quantitation of detected phosphopeptides between sample preparations through integration of the MRM traces ${ }^{7,9}$.

\section{$A T M$ and ATR in vitro phosphorylation of XCEP63}

In vitro phosphorylation of XCEP63 serine 560 was performed as follows. Briefly, Flag$A T M$ or Flag-ATR proteins were purified as previously described ${ }^{6}$ and incubated in $20 \mu \mathrm{l}$ of EB kinase buffer (20 mM HEPES [pH 7.5], $50 \mathrm{mM} \mathrm{NaCl}, 10 \mathrm{mM} \mathrm{MgCl}, 1 \mathrm{mM}$ DTT, 1 $\mathrm{mM} \mathrm{NaF}, 1 \mathrm{mM} \mathrm{Na}_{3} \mathrm{VO}_{4}$, and $10 \mathrm{mM} \mathrm{MnCl}$ ) supplemented with $50 \mu \mathrm{M} \mathrm{ATP}, 1 \mu \mathrm{l}$ of $\gamma$ ${ }^{32} \mathrm{P}$-ATP $10 \mathrm{mCi} / \mathrm{\mu l}$ (greater than $3,000 \mathrm{Ci} / \mathrm{mmol}$ ) and $0.5 \mathrm{mg} / \mathrm{ml} 50 \mathrm{mer} X C E P 63$ peptides containing serine or alanine 560 at the $25^{\text {th }}$ aminoacid. Samples were incubated at $30^{\circ} \mathrm{C}$ for $20 \mathrm{~min}$, and reactions were spotted on p81 phosphocellulose filter paper (Upstate Biotechnology, Lake Placid, New York, United States). Filters were air-dried and washed three times in 5\% phosphoric acid. Radioactivity was quantified by scintillation counting.

\section{Production, purification and characterization of anti XCEP63 phospho serine 560 antibodies.}

N-terminus Cysteine-20 mer XCEP63 peptides containing phosphorylated serine 560 at position 10 produced by the LRI peptide facility were conjugated to KLH (Pierce) according to manufacturer instruction and injected into 8 rabbits (Harlan). Serum from each rabbit was collected and screened for the ability to recognize phosphorylated-only recombinant and endogenous XCEP63. IgGs specific for phopho-S560 were further purified according to standard procedures. Briefly, rabbit serum was purified using affinity columns. To prepare affinity columns CNBr-activated sepharose 4B beads (GE Healthcare) were dissolved in $1 \mathrm{mM} \mathrm{HCl}$ and packed into Econo-Pac Column (Bio-Rad Laboratories). $5 \mathrm{mg}$ of non-phospho-S560 or phosho-S560 peptides were dissolved in 5

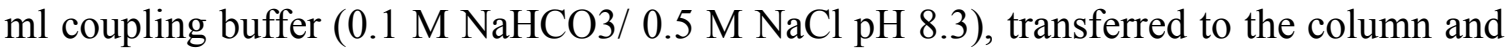
incubated for 2 hours at room temperature under rotator. After incubation, the columns were washed with $30 \mathrm{ml}$ of coupling buffer then $200 \mathrm{ml}$ of $0.1 \mathrm{M}$ Tris-HCl pH 8 and 200 $\mathrm{ml}$ of $0.1 \mathrm{M}$ Tris- $\mathrm{HCl} \mathrm{pH} \mathrm{8/0.5} \mathrm{M} \mathrm{NaCl}$. Two different rabbit serum (1645 and 1797) were filtered through $0.22 \mathrm{um}$ Millex GP filter unit (Millipore). $20 \mathrm{ml}$ of each serum were first loaded onto phospho-S560 column. Flow-through was collected and re-loaded onto the column for at least 5 times. Column was washed with $200 \mathrm{ml} 0.1 \mathrm{M}$ Tris- $\mathrm{HCl} \mathrm{pH}$ $8 / 0.5 \mathrm{M} \mathrm{NaCl}$. Antibodies were eluted by adding $10 \mathrm{ml} 0.1 \mathrm{M}$ Glycine/ $0.5 \mathrm{M} \mathrm{NaCl} \mathrm{pH}$ 2.5. $500 \mu \mathrm{l}$ eluted fractions were collected in Eppendorf tube pre-filled with $50 \mu 1$ of $1 \mathrm{M}$ Tris- $\mathrm{HCl} \mathrm{pH} \mathrm{8.} \mathrm{The} \mathrm{eluted} \mathrm{IgGs} \mathrm{were} \mathrm{sequentially} \mathrm{loaded} \mathrm{onto} \mathrm{non-phospho-S560}$ column to eliminate non-phospho-S560 specific IgGs. 


\section{DNA replication in egg extract}

DNA replication was monitored as previously described ${ }^{5}$. Briefly, 2000 nuclei/ $\mu 1$ were incubated in untreated, mock depleted and XCEP63 depleted interphase egg extracts in the presence and in the absence of $0.1 \mathrm{U} / \mu 1$ EcoRI or $0.1 \mathrm{U} / \mu \mathrm{L} E c o R I$ and $3 \mathrm{mM}$ caffeine. Extracts were supplemented with $10 \mu \mathrm{Cu}$ of $\alpha^{32} \mathrm{P}$-dATP and incubated for 2 hours at room temperature. Reactions were stopped with stop buffer ( $8 \mathrm{mM}$ EDTA, $80 \mathrm{mM}$ Tris pH8.0, $1 \%$ SDS), supplemented with $1 \mathrm{mg} / \mathrm{ml}$ Proteinase $\mathrm{K}$ and incubated at $37^{\circ} \mathrm{C}$ for 1 hour. Genomic DNA was isolated by phenol-chloroform-ethanol extraction and run on agarose gels, which were dried and exposed. Radioactivity incorporation was monitored and quantified by phosphoimager.

\section{Isolation of avian $C E P 63$ and $C E P 63$ knockout in DT40 cells}

Avian full length CEP63 cDNA was isolated from avian DT40 B cell cDNA generated with Invitrogen's Superscript III kit with OligodT primers and fully sequenced on both DNA strands. To construct the targeting vectors, oligonucleotide primers designed from the sequence of avian CEP63 cDNA were used to PCR amplify segments of the genomic locus using DT40 DNA as a template. Two arms of homology were synthesized and cloned into pBluescript II $\mathrm{kS}+$ plasmid (Stratagene) using 5'TTGGGGAGCTTATCAGATGG-3'/5' -GCTGGTGTCAGCCTCTCACAA-3' primers for the left arm and 5'-TAGAGAAGCAGTATGTGCTGC-3'/5'TACCTCCCTCTGCTGCAG-3' for right arm. Both arms were cloned at BamHI. Selection markers (Histidinol and Blasticidin S resistant cassettes) were inserted between two arms at BamHI site. The targeting constructs were designed to disrupt the structure of the CEP63 gene and to delete most of CEP63 encoding large exons (9 to 14) so that any residual truncated polypeptide encoded by the targeted alleles would be non-functional. To generate CEP63-deficient DT40 clones, two rounds of targeting were performed to disrupt both CEP63 alleles. Cells were electroporated with the targeting vector using a Gene Pulser (BioRad) and drug-resistant clones selected in Histidinol (Sigma) to obtain hemizygous $C E P 63^{+-}$cells. Few hemizygous clones were then electroporated with the Blasticidin S targeting vector and selected in Blasticidin S (Sigma). CEP63 $3^{-/}$clones were obtained with a frequency of $20 \%$. Drug-resistant clones were screened by Southern blot. Southern hybridization was done with $\alpha^{32} \mathrm{P}$-dCTP labelled probe generated with Megaprime DNA labeling kit (GE Healthcare). Probe fragment was amplified from genomic DNA using 5'-ATCGGATCAGACAGGAACTGTG-3'/5'AGAGCTGCAATTCAACCTGACT-3' primer pairs. DT40 cells genomic DNA was digested with BamHI/BglII double restriction enzymes. To analyse CEP63 mRNA expression total RNA was extracted according to manufacturer's protocol (Sepasol, Nacalai Tesque). cDNA synthesis was done with Invitrogen's Superscript III kit. RTPCR of CEP63 gene was obtained with the following primers : (5'AAGCACAGAGGAAGGCTTTG-3'/5'-GTGGCTCTGAGCTCCATCTT-3' ). $\quad \beta$-actin primers were used as control. CEP63 protein as analyzed by western blotting with anti chicken CEP63 antibodies used 1:500 in 2\%BSA/PBS. More detailed protocols are available upon request. 


\section{DT40 cell culture}

Cell culture and transfection of DT40 cells were done as previously described ${ }^{10}$. Briefly DT40 B lymphoma cells were grown in DMEM (Gibco) containing 10\% fetal bovine serum, $1 \%$ chicken serum, $10^{-5} \mathrm{M}$-mercaptoethanol, penicillin, streptomycin, at $39.5^{\circ} \mathrm{C}$. Cells were irradiated with a source of ${ }^{137} \mathrm{Cs}$, or treated with $2.5 \mathrm{mM}$ thymidine, 0.1 $\mu \mathrm{g} / \mathrm{ml}$ nocodazole and $10 \mu \mathrm{g} / \mathrm{ml}$ of BrdU (all from Sigma) as appropriate.

\section{Growth curves and survival}

For growth curve experiments, viable and dead cells were distinguished by trypan blue staining exclusion and optic microscope or FACS analysis. For FACS (flow cytometric) analysis cells grown with or without BrdU were collected, washed twice in ice-cold PBS and fixed in $70 \%$ ethanol in PBS for 15 minutes on ice. After fixation, cells were washed and treated with RNase A $(100 \mu \mathrm{g} / \mathrm{ml})$ in PBS for 30 minutes at room temperature. The cells were then stained with propidium iodide in PBS. Samples of 10.000 cells were then analysed on a FACS scan.

\section{Analysis of mitotic DT40 cells}

\section{Spindle and centrosome morphology}

Confocal analysis of mitotic CEP63 ${ }^{+/+}$and $C E P 63^{-/-}$DT40 cells was performed by cells that were asynchronous or arrested with $0.1 \mu \mathrm{g} / \mathrm{ml}$ nocodazole and released. Cells were collected onto slides by a cyto-centrifuge and fixed in 3\% paraformaldehyde in PBS for 15 minutes at room tempereature, permeabilized in 0.5\% NP-40 in PBS for 15 minutes at room temperature, rinsed 3 times in $0,5 \% \mathrm{BSA}$ for 1 hour at $37^{\circ} \mathrm{C}$ in and processed for immuno-staining with DAPI and anti $\alpha$-tubulin antibody detected with commercial secondary antibodies as previously described. For centrosome morphology DT40 cells stably transfected with GFP-CEP63 were treated with $1 \mu \mathrm{M}$ camptotechin (CPT) in the presence or absence of $5 \mathrm{mM}$ caffeine for 1 hour, collected and processed for immunostaining with anti $\alpha$-tubulin antibodies as described above. GFP-CEP63 was constructed according to standard protocols available upon request using EGFP encoding vector (Clonetech). Images were acquired with Zeiss Axiovert microscope equipped with Volocity software.

\section{Mitotic progression delay}

Mitotic $C E P 63^{+/+}$and $C E P 63^{-/-}$DT40 cells were obtained by a thymidine block induced by 8 hours incubation with $2.5 \mathrm{mM}$ thymidine (Sigma). Cells were then released in normal medium with no thymidine. At 2 hours from release when cells started to enter mitosis a batch of cells was irradiated at 10 Gys in the presence or in the absence of 5 $\mathrm{mM}$ caffeine. Irradiation was performed with a source of ${ }^{137} \mathrm{Cs}$. Irradiated and nonirradiated cells were collected every hour from thymidine release up to 8 hours and processed for immuno-staining with DAPI, anti $\alpha$-tubulin and anti histone $H 3$-phosphoSerine 10 (Abcam). Mitotic index for $C E P 63^{+/+}$and $C E P 63^{-/-}$cells was calculated by counting cells 300 cells for each time point. 


\section{Orthophosphate labelling to determine avian CEP63 phosphorylation status}

A total of $3 \times 10^{6}$ DT40 cells was pre-incubated in $12 \mathrm{ml}$ of phosphate-free RPMI 1640 medium for $1 \mathrm{~h}$. Cells were then incubated for 2 hours in the presence of $1 \mathrm{mCi}$ $\left[{ }^{32} \mathrm{P}\right]$ orthophosphate. Where indicated cells were irradiated with $10 \mathrm{Gys}$ in the presence or in the absence of $5 \mathrm{mM}$ Caffeine, collected, washed, and resuspended in PBS. Cells were then lysed in buffer containing $25 \mathrm{mM}$ HEPES, $\mathrm{pH} 7.5,150 \mathrm{mM} \mathrm{NaCl}, 5 \mathrm{mM}$ EDTA, 1 $\mathrm{mM}$ sodium orthovanadate, $1 \mathrm{mM}$ sodium fluoride, $10 \mu \mathrm{g} / \mathrm{ml}$ leupeptin, and $10 \mu \mathrm{g} / \mathrm{ml}$ aprotinin. Lysates were centrifuged at $14,000 \times \mathrm{g}$ for 10 minutes at $4^{\circ} \mathrm{C}$. The supernatants were pre-cleared by incubation with protein A-Sepharose for $1 \mathrm{~h}$ at $4{ }^{\circ} \mathrm{C}$. The unbound fraction was then subjected to immunoprecipitation by the addition of $30 \mu \mathrm{l}$ of protein ASepharose only (Mock) or $30 \mu 1$ of protein A-Sepharose that had been previously incubated with $100 \mu \mathrm{l}$ of affinity purified anti chicken CEP63 antibodies (CEP63 IP) (0.4 $\mathrm{mg} / \mathrm{ml}$ ). Columns made with the immobilized peptides used to immunize the rabbits were used to for antibody purification essentially as described in the previous paragraph. The immune complexes were washed 5 times with RIPA buffer $(150 \mathrm{mM} \mathrm{NaCl}, 10 \mathrm{mM}$ Tris/ $\mathrm{HCl}, \mathrm{pH} 7.2,1 \%$ sodium deoxycholate, $1 \%$ Triton $\mathrm{X}-100,0.1 \% \mathrm{SDS}$ ), dissociated in SDS-sample buffer, and separated by SDS-PAGE and detected by autoradiography.

For avian CEP63 western blot samples from DT40 cells extracts obtained as described above were diluted in loading buffer, boiled for 3 minutes, electrophoresed on SDS-PAGE, transferred to nitrocellulose membranes, and probed with anti CEP63 polyclonal antibodies.

\section{Supplementary references}

1 V. Costanzo, T. Paull, M. Gottesman et al., PLoS Biol 2 (5), E110 (2004).

2 A. Desai, A. Murray, T. J. Mitchison et al., Methods Cell Biol 61, 385 (1999).

3 R. Heald, R. Tournebize, T. Blank et al., Nature 382 (6590), 420 (1996).

$4 \quad$ K. D. Lustig, P. T. Stukenberg, T. J. McGarry et al., Methods Enzymol 283, 83 (1997).

$5 \quad$ K. Trenz, A. Errico, and V. Costanzo, Embo J 27 (6), 876 (2008).

$6 \quad$ K. Trenz, E. Smith, S. Smith et al., Embo J 25 (8), 1764 (2006).

7. Cox DM, Zhong F, Du M, Duchoslav E, Sakuma T and McDermott JC J. Biomol. Techn. 16, 83-90 (2005).

8. Williamson BL, Marchese J and Morrice NA, Mol. Cell. Proteomics 5, 337-346 (2006).

9. Unwin RD, Griffiths JR, Leverentz MK, Grallert A, Hagan IM and Whetton AD Mol. Cell. Proteomics 4, 1134-1144 (2005).

10. Sonoda E, Sasaki MS, Buerstedde JM, Bezzubova O, Shinohara A, Ogawa H, Takata M, Yamaguchi-Iwai Y, Takeda S (1998). Embo J 17: 598-608 